\title{
The climate impact of aerosols on the lightning flash rate: is it detectable from long-term measurements?
}

\author{
Qianqian Wang ${ }^{1}$, Zhanqing $\mathrm{Li}^{1,2}$, Jianping $\mathrm{Guo}^{3}$, Chuanfeng Zhao ${ }^{1}$, and Maureen $\mathrm{Cribb}^{2}$ \\ ${ }^{1}$ State Laboratory of Earth Surface Process and Resource Ecology, College of Global Change and Earth System Science, \\ Beijing Normal University, Beijing, China \\ ${ }^{2}$ Department of Atmospheric and Oceanic Science, Earth System Science Interdisciplinary Center, University of Maryland, \\ College Park, MD, USA \\ ${ }^{3}$ State Key Laboratory of Severe Weather, Chinese Academy of Meteorological Sciences, Beijing, China
}

Correspondence: Zhanqing Li (zli@atmos.umd.edu) and Jianping Guo (jpguocams@gmail.com)

Received: 11 March 2018 - Discussion started: 4 April 2018

Revised: 26 July 2018 - Accepted: 6 August 2018 - Published: 6 September 2018

\begin{abstract}
The effect of aerosols on lightning has been noted in many case studies, but much less is known about the long-term impact, relative importance of dynamicsthermodynamics versus aerosol, and any difference by different types of aerosols. Attempts are made to tackle all these factors, whose distinct roles are discovered by analyzing 11-year datasets of lightning, aerosol loading and composition, and dynamic-thermodynamic data from satellite and model reanalysis. Variations in the lightning rate are analyzed with respect to changes in dynamic-thermodynamic variables and indices such as the convective available potential energy (CAPE) and vertical wind shear. In general, lightning has strong diurnal and seasonal variations, peaking in the afternoon and during the summer. The lightning flash rate is much higher in moist central Africa than in dry northern Africa presumably because of the combined influences of surface heating, CAPE, relative humidity (RH), and aerosol type. In both regions, the lightning flash rate changes with aerosol optical depth (AOD) in a boomerang shape: first increasing with AOD, tailing off around AOD $=0.3$, and then behaving differently, i.e., decreasing for dust and flattening for smoke aerosols. The deviation is arguably caused by the tangled influences of different thermodynamics (in particular humidity and CAPE) and aerosol type between the two regions. In northern Africa, the two branches of the opposite trends seem to echo the different dominant influences of the aerosol microphysical effect and the aerosol radiative effect that are more pronounced under low and high aerosol loading conditions, respectively. Under low-AOD conditions,
\end{abstract}

the aerosol microphysical effect more likely invigorates deep convection. This may gradually yield to the suppression effect as AOD increases, leading to more and smaller cloud droplets that are highly susceptible to evaporation under the dry conditions of northern Africa. For smoke aerosols in moist central Africa, the aerosol invigoration effect can be sustained across the entire range of AOD by the high humidity and CAPE. This, plus a potential heating effect of the smoke layer, jointly offsets the suppression of convection due to the radiative cooling at the surface by smoke aerosols. Various analyses were done that tend to support this hypothesis.

\section{Introduction}

Lightning can be considered a key indicator of strong atmospheric convection (Betz et al., 2009). Lightning activity has been linked to two major factors: dynamics-thermodynamics and aerosols (e.g., Lucas et al., 1994; Michalon et al., 1999; Boccippio et al., 2000; Orville et al., 2001; Williams and Stanfill, 2002; Christian et al., 2003; Williams et al., 2004, 2005; Bell et al., 2008, 2009; Guo et al., 2016).

Since the pioneering work by Westcott (1995), who attempted to link summertime cloud-to-ground lightning activity to anthropogenic activities, the roles of aerosols in lightning have been increasingly recognized, as comprehensively reviewed on the topic associated with aerosol-cloudprecipitation interactions (e.g., Tao et al., 2012; Fan et al., 2016; Li et al., 2016, 2017a). The aerosol effect encom- 
passes both radiative and microphysical effects (Boucher et al., 2013; Li et al., 2017b). The radiative effect suggests that aerosols can heat the atmospheric layer and cool the surface by absorbing and scattering solar radiation, thereby reducing the latent heat flux and stabilizing the atmosphere (Kaufman et al., 2002; Koren et al., 2004, 2008; Li et al., 2017a). Convection and electrical activities are thus likely inhibited (Koren et al., 2004). By acting as cloud condensation nuclei $(\mathrm{CCN})$ with fixed liquid water content, increasing the aerosol loading tends to reduce the mean size of cloud droplets, suppress coalescence, and delay the onset of warmrain processes (Rosenfeld and Lensky, 1998). This permits more liquid water to ascend higher into the mixed-phase region of the atmosphere where it fuels lightning. A conspicuous enhancement of lightning activity was found to be tightly connected to volcanic ash over the western Pacific Ocean (Yuan et al., 2011). More than a $150 \%$ increase in lightning flashes accompanied a $\sim 60 \%$ increase in aerosol loading. Aerosol emissions from ships enhanced the lightning density by a factor of $\sim 2$ along two of the world's main shipping lanes in the equatorial Indian Ocean (Thornton et al., 2017). In terms of the response of clouds to aerosols, an optimal aerosol concentration was found to exist based on observational analyses (Koren et al., 2008; Wang et al., 2015) and a theoretical calculation (Rosenfeld et al., 2008). Biomassburning activities, anthropogenic emissions, and desert dust are the three major atmospheric aerosol sources (Rosenfeld et al., 2001; Fan et al., 2018) that have different climate effects. The increased rainfall in southern China and drought in northern China are thought to be related to an increase in black carbon aerosols (Menon et al., 2002). The effect of dust on cloud properties tends to decrease precipitation through a feedback loop (Rosenfeld et al., 2001; Huang et al., 2014a, b) especially for drizzle and light rain.

Most studies on aerosol-convection interactions account for the aerosol burden (i.e., aerosol optical depth, AOD; the number concentration of aerosols; particulate matter that have a diameter less than $2.5 \mu \mathrm{m}$; or $\mathrm{CCN}$ ) rather than aerosol size or species. It was not until recently that ultrafine aerosol particles were found to intensify convective strength by being activated into cloud droplets under excess supersaturation environmental conditions (Fan et al., 2018). Regarding aerosol species, recent studies have underscored the urgent need to consider the effect of different aerosol species in modulating lightning activity (e.g., Stolz et al., 2015, 2017), prompting us to perform more detailed analyses in this study.

Lightning and convection strength are controlled by various dynamic-thermodynamic variables and indices such as air temperature (Price, 1993; Williams, 1994, 1999; Markson, 2007), convective available potential energy (CAPE) and its vertical distribution (normalized CAPE, NCAPE) (Stolz et al., 2015; Bang and Zipser, 2016), vertical wind shear (Khain et al., 2008; Fan et al., 2009, 2013; Igel and Heever, 2015; Bang and Zipser, 2016), relative humidity (RH) in the lower and middle troposphere (Fan et al., 2007;
Wall et al., 2014), cloud base height (Williams et al., 2005), updraft velocity (Zipser and Lutz, 1994; Williams et al., 2005), and warm cloud depth (Stolz et al., 2015, 2017).

Depending on aerosol properties and atmospheric conditions, aerosols may enhance (Khain et al., 2005, 2008; Fan et al., 2007) or suppress convection (Rosenfeld et al., 2001; Khain et al., 2004; Zhao et al., 2006). In general, aerosols tend to suppress convection for isolated clouds forming in relatively dry conditions but invigorate convection in convective systems within a moist environment (Fan et al., 2009). Under conditions of strong vertical wind shear, aerosols tend to reduce the strength of single deep convective clouds due to higher detrainment and larger evaporation of cloud hydrometeors (Richardson et al., 2007; Fan et al., 2009). The increase in evaporation and cooling intensifies downdrafts and fosters the formation of secondary clouds, cloud ensembles, and squall lines (Altaratz et al., 2010). Apart from the invigoration effect induced by aerosols, lightning activity is enhanced by increases in NCAPE, cloud base height, and vertical wind shear, but inhibited by the increasing cloud base height (Williams and Satori, 2004; Williams, 2005), midtropospheric relative humidity, and warm cloud depth (Stolz et al., 2015).

Most previous studies were based on short-term data. Here, we investigate and quantify the relative roles of aerosols and dynamics-thermodynamics on the lightning flash rate using long-term (11 years) lightning, AOD, and dynamic-thermodynamic data. Section 2 describes the datasets and method used in this study; Sect. 3 shows the regions of interest (ROIs); and Sect. 4 examines (1) the climatological behavior of the lightning flash rate and AOD, (2) the response of the lightning flash rate to dynamics and thermodynamics, (3) the contrast in the response of the lightning flash rate to dust and smoke, (4) the environmental dependence of the aerosol effect, and (5) the relative roles of dynamics, thermodynamics, and AOD on the lightning flash rate. A summary of key findings is given in Sect. 5 .

\section{Data and method}

\subsection{Data}

\subsubsection{Lightning data}

We use lightning data from the Lightning Imaging Sensor (LIS) onboard the Tropical Rainfall Measuring Mission (TRMM) satellite which was designed to acquire and investigate the distribution and variability of total lightning (i.e., intra-cloud and cloud-to-ground) on a global basis and spans all longitudes between $38^{\circ} \mathrm{N}$ and $38^{\circ} \mathrm{S}$ during the day and night (Boccippio, 2002; Christian et al., 2003). The LIS on TRMM monitors individual storms and storm systems at a nadir field of view exceeding $580 \mathrm{~km} \times 580 \mathrm{~km}$ with a detection efficiency of $69 \%$ to $90 \%$. Also used are the low- 
resolution monthly time series (LRMTS) from 2003 to 2013, which is a gridded lightning climatology dataset that provides the flash rate per month at a $2.5^{\circ} \times 2.5^{\circ}$ spatial resolution and is recorded in coordinated universal time. The low-resolution diurnal climatology provides the mean diurnal cycle in local solar time (LT) with the same spatial resolution (Cecil et al., 2001, 2006, 2014).

\subsubsection{Aerosol data}

Aerosol loading is characterized by AOD which is obtained from observations collected by the Moderate Resolution Imaging Spectroradiometer (MODIS) onboard the Aqua satellite that crosses the Equator at $\sim 13: 30$ LT. Here, the monthly level 3 global product (MYD08_M3) on a $1^{\circ} \times 1^{\circ}$ grid from 2003 to 2013 is used. The AOD at $0.55 \mu \mathrm{m}$ is retrieved using the dark-target-deep-blue combined algorithm which is particularly suitable over desert regions (Levy et al., 2013; Hubanks et al., 2015). The Modern-Era Retrospective Analysis for Research and Application (MERRA) is a NASA meteorological reanalysis that takes advantage of satellite data from 1979 to the present using the Goddard Earth Observing System Data Assimilation System version 5 (GEOS-5). The assimilation of AOD in the GEOS-5 involves very careful cloud screening and data homogenization by means of a neural net scheme that translates MODIS radiances into Aerosol Robotic Network (AERONET)-calibrated AODs. The MERRA Aerosol Reanalysis (MERRAero) provides dust, black carbon (BC), organic carbon (OC), and total extinction AODs, and the total Ångström exponent at a spatial resolution of $0.625^{\circ} \times 0.5^{\circ}$ (da Silva et al., 2015). These data characterize aerosol species and particle size.

\subsubsection{Dynamic-thermodynamic data}

Dynamic-thermodynamic data used are from the European Centre for Medium-Range Weather Forecasts (ECMWF) ERA-Interim reanalysis product (Dee et al., 2011). Of interest to this study are the surface upward sensible heat flux, the surface upward latent heat flux, sea level pressure (SLP), $2 \mathrm{~m}$ temperature, CAPE, relative humidity at 700 and $500 \mathrm{hPa}$, the wind fields at 925 and $500 \mathrm{hPa}$, and divergence at $200 \mathrm{hPa}$, all with a spatial resolution of $1^{\circ} \times 1^{\circ}$. With reference to the findings from previous studies, we choose the following factors to characterize the dynamics and thermodynamics.

CAPE. CAPE is a thermodynamic parameter commonly used in strong convection analysis and forecasting. It describes the potential buoyancy available to idealized rising air parcels and thus denotes the instability of the atmosphere (Riemann-Campe et al., 2009; Williams, 1992). The stronger CAPE is, the more unstable the atmosphere is and the more likely strong vertical air motion is. Lightning activity increases with CAPE (Williams et al., 2002). The conversion efficiency of CAPE to updraft kinetic energy depends on the strength and width of updrafts (Williams et al., 2005). However, reliable updraft measurements that would illuminate this role in the present study are lacking.

Sea level pressure. Atmospheric pressure is a key dynamic factor affecting weather because it defines basic weather regimes. Low-pressure systems are usually associated with strong winds, warm air, and atmospheric lifting and normally produce clouds, precipitation, and strong convective disturbances such as storms and cyclones. An examination of summertime sea level pressure anomalies in the tropical Atlantic region shows an inverse relationship between sea level pressure and tropical cyclones (Knaff, 1997).

Potential temperature. Many researchers have studied the role of temperature in influencing lightning activity (Williams, 1992, 1994, 1999; Williams et al., 2005; Markson, 2003, 2007). However, the direct comparison of air temperatures for different regions is problematic because air temperature systematically declines with altitude. We choose potential temperature instead, which corrects for the altitude dependence and provides a more meaningful comparison. Taking into account that the linkage between lightning activity and thermodynamics involves moist processes, some others use wet-bulb temperature or wet-bulb potential temperature, which includes both temperature and moisture (Williams, 1992; Reeve and Toumi, 1999; Jayaratne and Kuleshov, 2006). It has been demonstrated that CAPE increases linearly with wet-bulb potential temperature (Williams et al., 1992). In this study, we would like to examine the relative roles of several parameters and their total contribution to lightning activity. In order to select more independent variables and reduce the duplication of temperature and humidity information, potential temperature is selected. Although it does not reflect moist processes directly, when the moisture level is suitable, places with higher temperatures are more favorable for convection. Here, potential temperature $(\theta$; in units of $\mathbf{K})$ is calculated from $2 \mathrm{~m}$ air temperature $(T$; in units of $\mathrm{K})$ and pressure $(p$; in units of $\mathrm{hPa})$ :

$\theta=T\left(\frac{1000}{p}\right)^{0.286}$.

Mid-level relative humidity. Moderately wet underlying surfaces are an important factor in facilitating deep convection due to the compromise between instability energy (when temperature is fixed, the atmosphere is wetter and CAPE is larger) and the transformation efficiency from instability energy to kinetic energy (when the boundary layer is wetter, the cloud base height is lower and updrafts are weaker). Higher surface relative humidity results in more lightning activities in dry regions and fewer lightning activities in wet regions with the watershed of surface relative humidity values at $\sim 72 \%$ to $74 \%$ (Xiong et al., 2006). However, for midlevel humidity, only shallow convection occurs in the driest case while strong deep convection occurs in more moist cases (Derbyshire et al., 2004). Strong positive relations are found 
between mean humidity (between 2 and $6 \mathrm{~km}$ ) and convective cloud top heights (Redelsperger et al., 2002). Anomalously high humidity in the free troposphere (between 850 and $400 \mathrm{hPa}$ ), which tends to increase plume buoyancy, is observed prior to a shallow-to-deep convection transition (Chakraborty et al., 2018). Different from surface moisture as a cause of deep convection, mid- to upper-tropospheric moisture (between 200 and $600 \mathrm{hPa}$ ) is more likely to be an effect of convection (Sobel et al., 2003). In addition, moistening the mid-tropospheric environment can also reduce the dilution effect on CAPE, which depends strongly on the degree of subsaturation of the entrained air: the wetter the entrained air, the smaller the effect (Zhang, 2009) which tends to facilitate ensuing deep convection. Therefore, there may be no turning point regarding the response of lightning to mid-level relative humidity. Even if there is, the 3-monthmoving-average mid-level relative humidity (less than $1 \%$ and $9 \%$ of the total in the dust- and smoke-dominant regions, respectively, surpass relative humidity $=73 \%$ ) is less than the surface relative humidity $(12 \%$ and $63 \%$ of the total in the dust- and smoke-dominant regions surpass relative humidity $=73 \%$ ) in the long term. Mean relative humidity values at 700 and $500 \mathrm{hPa}$ levels are used in this study.

Wind shear. The vertical shear of horizontal wind, hereafter simply referred to as wind shear, not only affects dynamical flow structures around and within a deep convective cloud (Rotunno et al., 1988; Weisman and Rotunno, 2004; Coniglio et al., 2006), but also qualitatively determines whether aerosols suppress or enhance convective strength (Fan et al., 2009). Bang and Zipser (2016) found no significant visible differences in wind shear (the lowest $200 \mathrm{hPa}$ ) between flashing and non-flashing radar precipitation features in the central Pacific. Others have suggested that vertical wind shear can suppress cloud vertical development for isolated convection (Richardson et al., 2007) but is critical in organizing mesoscale convection systems (Takemi, 2007). In this paper, wind shear (SHEAR; in units of $\mathrm{Pa} \mathrm{s}^{-1}$ ) is calculated from daily wind fields $\left((U, V)\right.$; in units of $\left.\mathrm{Pa} \mathrm{s}^{-1}\right)$ at 925 and $500 \mathrm{hPa}$ as follows:

$\operatorname{SHEAR}=\sqrt{\left(U_{500}-U_{925}\right)^{2}+\left(V_{500}-V_{925}\right)^{2}}$.

Divergence. Air divergence is especially useful because it can be linked to adiabatic heating processes, of which the nonuniformity gives rise to atmospheric motion (Mapes and Houze Jr., 1995; Homeyer et al., 2014). Fully developed clouds are usually accompanied by upper-level divergence, especially in raining regions (Mapes and Houze Jr., 1993). A pronounced divergence maximum exists between 300 and $150 \mathrm{hPa}$ due to deep convective outflow (Mitovski et al., 2010).

The surface property which determines the contribution of latent heat versus sensible heat is described by the Bowen ratio. In warm and wet climates, the large potential for evapotranspiration creates small Bowen ratios. In dry regions, a lack of water to evaporate creates large Bowen ratios. The Bowen ratio is calculated as

Bowen ratio $=\frac{\text { surface upward sensible heat flux }}{\text { surface upward latent heat flux }}$.

\subsection{Methodology}

\subsubsection{Data collocation}

A roughly 3-month running mean filter is used to smooth lightning data (i.e., the LRMTS dataset), allowing the LIS to progress twice through the diurnal cycle at a given location (Cecil et al., 2014) and to show the normal annual variation in lightning activity due to the seasonal meridional migration of the Intertropical Convergence Zone (ITCZ; Waliser and Gautier, 1993; Thornton et al., 2017). A 3-month running mean is also applied to all AOD and dynamic-thermodynamic data, which are then resampled onto $2.5^{\circ} \times 2.5^{\circ}$ resolution grids in the climatological analysis. To make the comparison within the same AOD range and to increase the number of data samples, climatological features of lightning, AOD, dynamics, and thermodynamics under polluted and clean conditions are limited to cases with AOD $<1.0$ over the regions of interest. Since there are large differences in aerosol loading in different seasons and under different dynamic-thermodynamic conditions, we cannot use a specific set of values to distinguish between clean and polluted cases applicable to all months and all dynamic-thermodynamic conditions. So for each month and under each fixed dynamic-thermodynamic condition, all data are sorted according to AOD and divided into three equal sample subsets where the top third of the AOD range is labeled as polluted, and the bottom third is labeled as clean. To avoid a higher probability of misclassification of clouds and aerosols in high-AOD regimes (Platnick et al., 2003), to minimize the influence of hygroscopic growth in a humid environment (Feingold and Morley, 2003), and to retain enough samples especially in the lightning-deficient region, the AOD range in this study is set between 0 and 1 , following the work of Kaufman et al. (2005, AOD <0.6), Koren et al. $(2008, \mathrm{AOD}<0.8 ; 2012$, AOD < 0.3) and Altaratz et al. (2017, AOD <0.4). In addition, MODIS AOD is evaluated using daily AERONET AOD data (see Figs. S1 and S11, 2, 3 in the Supplement). Analyses are performed between clean and polluted subsets only to create sufficient contrast between the groups while retaining good sampling statistics (Koren et al., 2012).

\subsubsection{Statistical analysis method}

Correlation coefficients are used to measure the strength of the relationship between the lightning flash rate and individual predictors (sea level pressure, potential temperature, mid-level relative humidity, CAPE, wind shear, divergence, AOD). The Pearson correlation (Pearson, 1896) is commonly used to measure linear correlation. A partial correlation is 

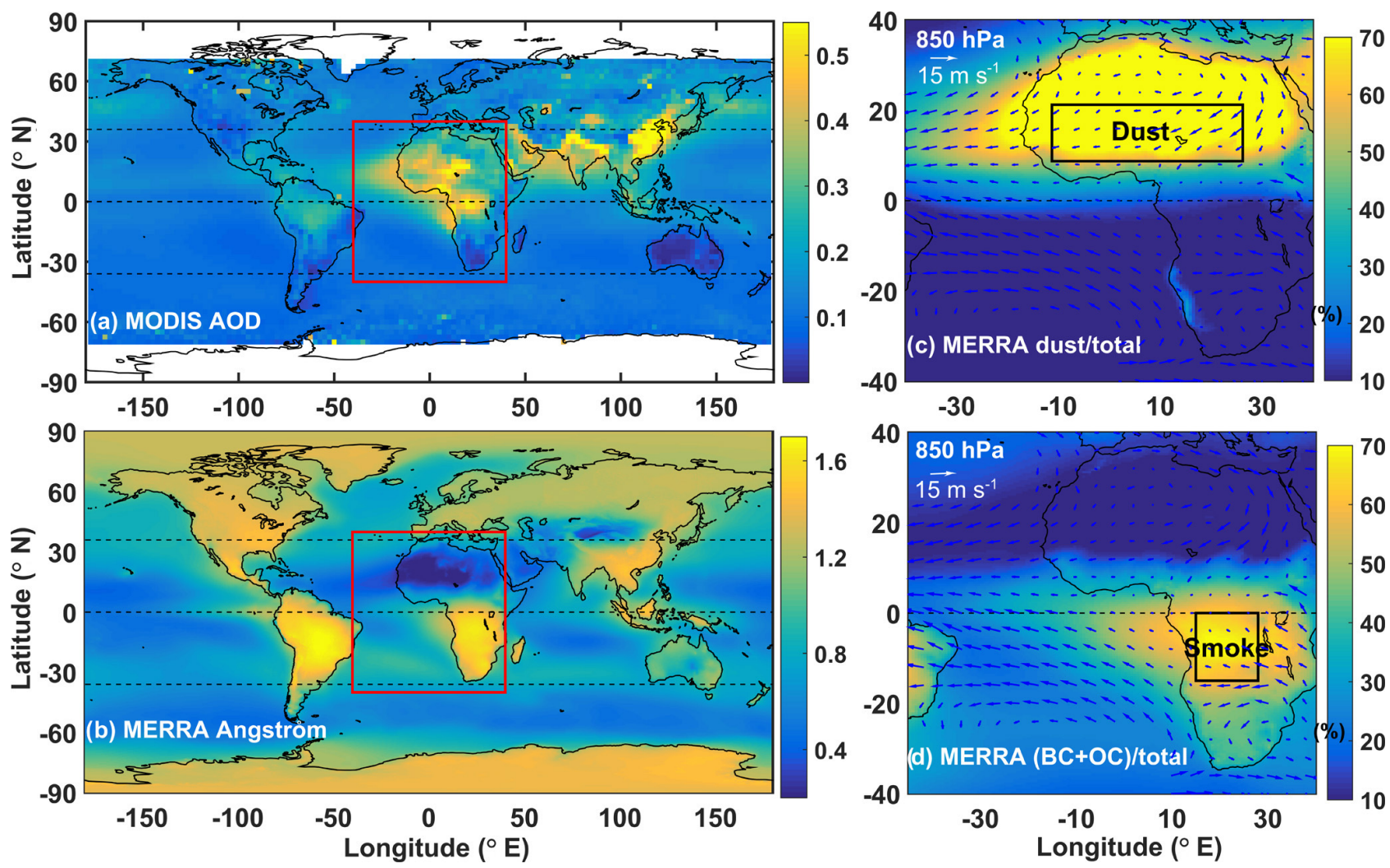

Figure 1. Spatial distributions of (a) aerosol optical depth (AOD) at $550 \mathrm{~nm}$ derived from the MODIS at a spatial resolution of $1^{\circ} \times 1^{\circ}$ and (b) the total aerosol Ångström parameter $(470-870 \mathrm{~nm})$ from the MERRA dataset on a $0.625^{\circ} \times 0.5^{\circ}$ grid for the period $2003-2013$ including all seasons. The red rectangle outlines the region of interest. (c) The ratio of dust AOD to total AOD over the region of interest and (d) the ratio of carbonaceous aerosol (black carbon and organic carbon: BC + OC) AOD to total AOD over the region of interest derived from the MERRAero dataset (da Silva et al., 2015). Also shown is the $850 \mathrm{hPa}$ mean wind field from the ERA-Interim reanalysis with a spatial resolution of $1^{\circ} \times 1^{\circ}$ in panels (c) and (d).

done to control the other predictors and to study the effect of each predictor separately. The correlation is significant when it passes the significance test at the 0.05 level.

To explore the relative roles of dynamic-thermodynamic variables and AOD on lightning activity, we use a multiplelinear regression method following previous studies (e.g., Igel and van den Heever, 2015; Stolz et al., 2017). Since there is an optimal value of aerosol loading in terms of the response of the lightning flash rate to aerosols (Koren et al., 2008; Rosenfeld et al., 2008), we establish standardized regression equations for AOD greater than and less than the turning point value. This is done to reduce the nonlinear effect of AOD. Note that all data used here are processed by averaging 10 samples sorted by AOD from small to large to mitigate data uncertainties. The standardized regression equation with seven predictor variables $x_{1}, x_{2}, \ldots, x_{7}$ (sea level pressure, potential temperature, mid-level relative humidity, CAPE, wind shear, divergence, AOD) and the response $y$ (lightning flash rate) can be written as

$y=\beta_{0}+\beta_{1} x_{1}+\beta_{2} x_{2}+\ldots+\beta_{i x_{i}, i=1, \ldots, 7}$.
Here, $y$ and $x_{i}$ are standardized variables derived from the raw variables $Y$ and $X_{i}$ by subtracting the sample means $(\bar{Y}$, $\left.\overline{X_{I}}\right)$ and dividing by the sample standard deviations $\left(\delta_{Y}, \delta_{i}\right)$ :

$y=\frac{Y-\bar{Y}}{\delta_{Y}}, x_{i}=\frac{X_{i}-\overline{X_{i}}}{\delta_{i}}, i=1, \ldots, 7$.

The sample mean of $N$ valid samples is calculated as

$\bar{Y}=\frac{\sum_{1}^{N} Y_{j}}{N}, \overline{X_{i}}=\frac{\sum_{1}^{N} X_{j i}}{N}, i=1, \ldots, 7 ; j=1, \ldots, N$.

The sample standard deviation is

$$
\begin{aligned}
\delta_{Y} & =\sqrt{\frac{1}{N-1} \sum_{1}^{N}\left(Y_{j}-\bar{Y}\right)^{2}}, \delta_{i}=\sqrt{\frac{1}{N-1} \sum_{1}^{N}\left(X_{j i}-\overline{X_{i}}\right)^{2}}, \\
i & =1, \ldots, 7 ; j=1, \ldots, N .
\end{aligned}
$$

Standardized regression coefficients ignore the independent variables' scale of units, which makes the slope estimates comparable and shows the relative weights to the changes in lightning flash rate. 


\section{Regions of interest (ROIs)}

High loadings of dust and smoke aerosols are found in northern and southern Africa, respectively, as seen in Fig. 1. Northern Africa is the world's largest source of mineral dust (Lemaître et al., 2010) with the most widespread, persistent dust aerosol plumes and the densest particulate contribution found on Earth (Prospero et al., 2002). About 2-4 billion tons of blown dust is estimated to be removed from the Sahara desert annually (Goudie and Middleton, 2001). Dust particles of relevance to atmospheric processes are minerals with particle sizes up to $70 \mu \mathrm{m}$ that can be readily suspended by the wind (Shao, 2008). Africa is also the single largest source of smoke emissions due to widespread biomass burning, accounting for roughly $30 \%$ to $50 \%$ of the total amount of vegetation burned globally each year (Andreae, 1991; van der Werf et al., 2003, 2006; Roberts et al., 2009). In central and southern Africa, biomass burning due to wildfires and human-set fires has strong diurnal and seasonal variabilities (Roberts et al., 2009; Ichoku et al., 2016).

Figure 1a shows the global distribution of mean AOD from the MODIS onboard the Aqua satellite from 2003 to 2013. Figure $1 \mathrm{~b}$ shows the Angström exponent obtained from the MERRAero at a spatial resolution of $0.625^{\circ} \times 0.5^{\circ}$ used for the analysis of contributions from different aerosol species, chiefly dust, black carbon, and organic carbon, and total extinction AODs. Note that satellite retrievals of the Ångström exponent have excessive uncertainties over land so they are not included in the MODIS Collection 6 product. The African continent stands out with very large AOD in two regions: the Sahara desert covered by dust (Fig. 1c) and central to southern Africa dominated by smoke (Fig. 1d), characterized by small and large values of the Ångström exponent, respectively (Fig. 1b). Due to their distinct differences in aerosol species, the dust- and smoke-dominant regions (Fig. 1c, d) are selected as the study regions for dust and smoke. The ratios of dust (dust-dominant region) or $(\mathrm{BC}+\mathrm{OC})$ (smoke-dominant region) extinction AOD to total extinction AOD are greater than $50 \%$ averaged over the period 2003-2013, which enables us to study multiple aerosol effects on lightning activity. Also shown in Fig. 1c and $\mathrm{d}$ are mean wind vectors at $850 \mathrm{hPa}$ over Africa and its neighboring oceans (the area outlined in red in the left panel), which represent the prevailing wind direction.

\section{Results and discussion}

\subsection{Climatological behavior of the lightning flash rate and AOD}

The seasonal and diurnal cycles of the lightning flash rate and AOD are first examined over the dust- and smoke-dominant regions (Fig. 2a). Figure 2 also shows the diurnal cycle (Fig. 2b) and monthly variations in the MODIS-retrieved
AOD and lightning flash rate (Fig. 2c, d) calculated under relatively clean and polluted (dusty/smoky) conditions over the dust-dominant region and the smoke-dominant region. The same afternoon peaks in lightning activity are seen in Fig. 2b, suggesting strong convection in the afternoon over land (Williams et al., 2000; Nesbitt and Zipser, 2003). Peaks in lightning activity over both the dust- and smoke-dominant regions under polluted (dusty/smoky) conditions occur $1 \mathrm{~h}$ later than those under clean conditions. This is consistent with the finding of an aerosol-induced delay in precipitation and lightning activity revealed from observations (Guo et al., 2016) and model simulations (Lee et al., 2016) in southern China. Numerous studies have noted that aerosols modulate convection and lightning activity through both radiative and microphysical processes, as reviewed extensively in Asia (Li et al., 2016) and around the world (Li et al., 2017b). Monthly variations in dust loading change little throughout the year (Fig. 2c), while smoke shows a pronounced seasonal variation with a large contrast between dry and wet seasons (Fig. 2d). Lightning activity in both regions is most active in summer and rarely occurs in winter, which is consistent with the seasonal feature of CAPE (especially for the smoke-dominant region; see Fig. 3), implying that the seasonal variation in lightning activity is mainly controlled by thermodynamic conditions. Figure 2 also shows an apparent enhancement in lightning activity under smoky conditions superimposed on both the diurnal (Fig. 2b) and seasonal cycles (Fig. 2d). Under dusty conditions, however, the impact is much weaker than under smoky conditions. Apart from different aerosol effects, different climate conditions that exist between the dust- and smoke-dominant regions, as well as between (i) heavy and (ii) light loading seasons and conditions for the same type of aerosol, may also contribute. A key factor is moisture, which is much lower over the dustdominant region (Bowen ratio $>10$, see Fig. S2 in the Supplement) than over the smoke-dominant region covered with rainforests (Bowen ratio $<0.4$, see Fig. S2 in the Supplement). The significantly higher probabilities of high relative humidity over the smoke-dominant region than over the dustdominant region for both middle troposphere and surface are shown in Fig. 4. The mean mid-level relative humidity for the dust-dominant region is $\sim 36 \%$ and for the smoke-dominant region it is $\sim 74 \%$. High values of relative humidity favor the invigoration effect (Fan et al., 2008, 2009; Khain et al., 2008; Khain, 2009; Thornton et al., 2017), which is likely a major cause of the intense lightning activity in the smokedominant region. The dust-dominant region is located in the vicinity of the African easterly jet (Burpee, 1972) and the smoke-dominant region is located in the ITCZ (Waliser and Gautier, 1993). Differences in wind shear and instability thus arise between the two regions. 

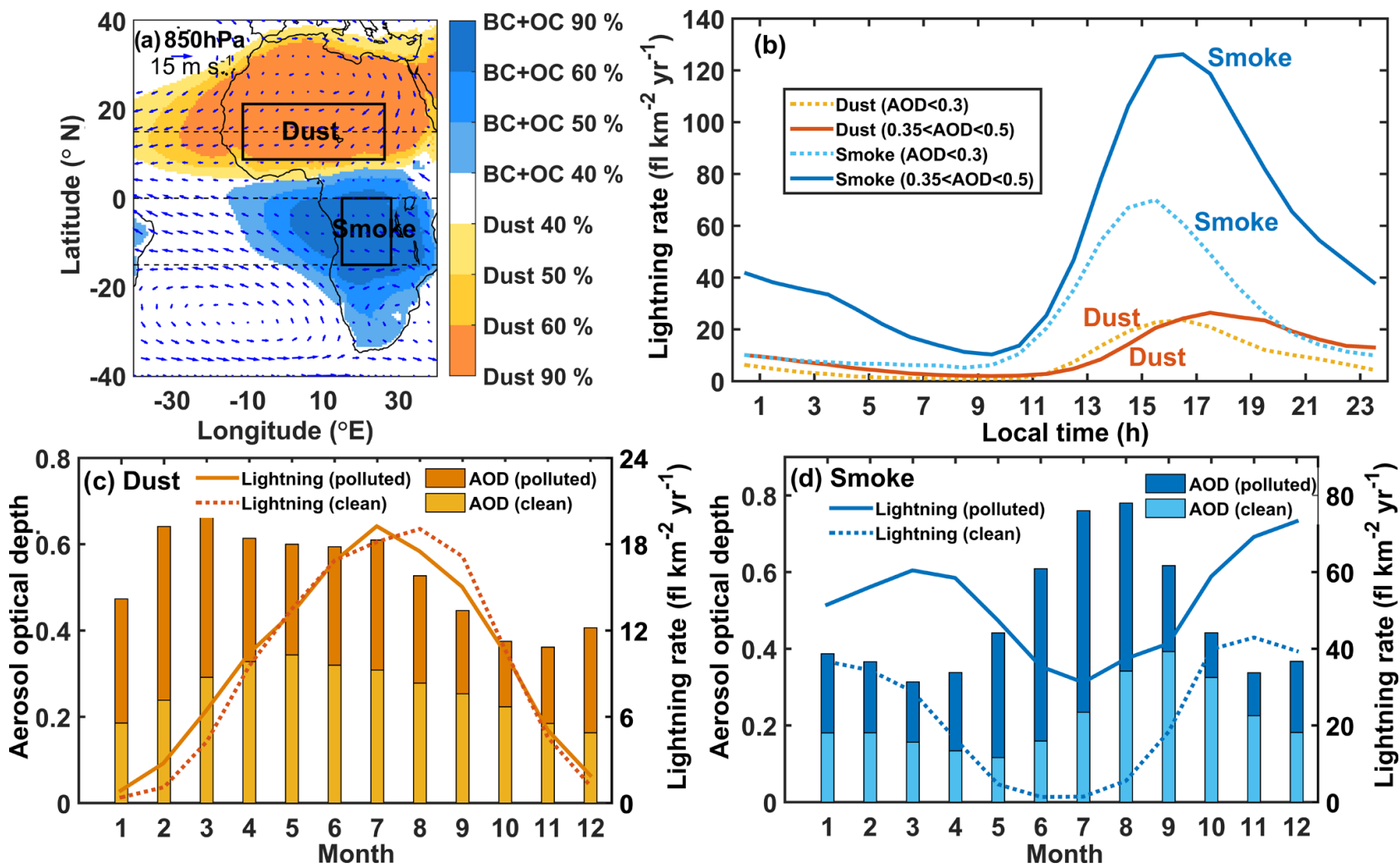

Figure 2. (a) The $850 \mathrm{hPa}$ mean wind field from the ERA-Interim reanalysis with a spatial resolution of $1^{\circ} \times 1^{\circ}$ showing the prevailing wind direction over Africa and the neighboring ocean over the region of interest defined in Fig. 1. The dust- and smoke-dominant regions (outlined by black rectangles) are defined as areas where the ratio of dust or carbonaceous aerosol (black carbon and organic carbon: $\mathrm{BC}+\mathrm{OC}$ ) extinction aerosol optical depth (AOD) to total extinction AOD is greater than $50 \%$ averaged over the period from 2003 to 2013 , which enables us to better understand the potential effect of dust or smoke aerosols on lightning. Also shown are the (b) diurnal cycle and monthly variations in mean AOD and lightning flash rate calculated under relatively clean and polluted (dusty/smoky) conditions in the (c) dustdominant region and the (d) smoke-dominant region. Unless otherwise noted, the AOD used in this study is derived from the MODIS, and the lowest (highest) third of the AOD range $(\mathrm{AOD} \in(0,1))$ is labeled as clean (polluted). Lightning flash rates come from the low-resolution monthly time series and the low-resolution diurnal climatology products on a $2.5^{\circ} \times 2.5^{\circ}$ grid (Cecil et al., 2001, 2006, 2014). Data from all seasons are included.

\subsection{Response of lightning to dynamics and thermodynamics}

Diurnal and seasonal variations in lightning activity depend on dynamic-thermodynamic conditions. We first look at the response of the lightning flash rate to dynamicthermodynamic conditions which are characterized by six variables (sea level pressure, potential temperature, CAPE, mid-level relative humidity, wind shear, and divergence). The cloud base height and warm cloud depth are also both physically relevant to lightning activity (Williams and Satori, 2004; Venevsky, 2014; Stolz et al., 2017). However, as statistical theory indicates, more factors will introduce more random noise and thus undermine the stability of the regression equation. When the sample size is fixed, the contribution of factors to the multiple regression equation changes little between 5 and 10 factors (Klein and Walsh, 1983; see Tables S1-1 and S1-2 in the Supplement), so 5-6 factors should be the best choice. However, the importance of these factors still needs to be assessed. Since cloud base height and warm cloud depth can be derived from temperature and humidity, to reduce the duplication of information about temperature and humidity, we choose to use only the fundamental variables relative humidity and potential temperature. The violin plot is an effective way to visualize the distribution of data and the shape of distributions that allows the quick and insightful comparison of multiple distributions across several levels of categorical variables. It synergistically combines the box plot and the density trace into a single display (Hintze and Nelson, 1998).

Figure 5 shows linear correlations between the lightning flash rate and the six dynamic-thermodynamic variables for the dust-dominant region. CAPE, mid-level relative humidity, and divergence are the top three dynamicthermodynamic variables strongly and positively correlated with lightning flash rate $(R>0.7)$. This suggests that high 


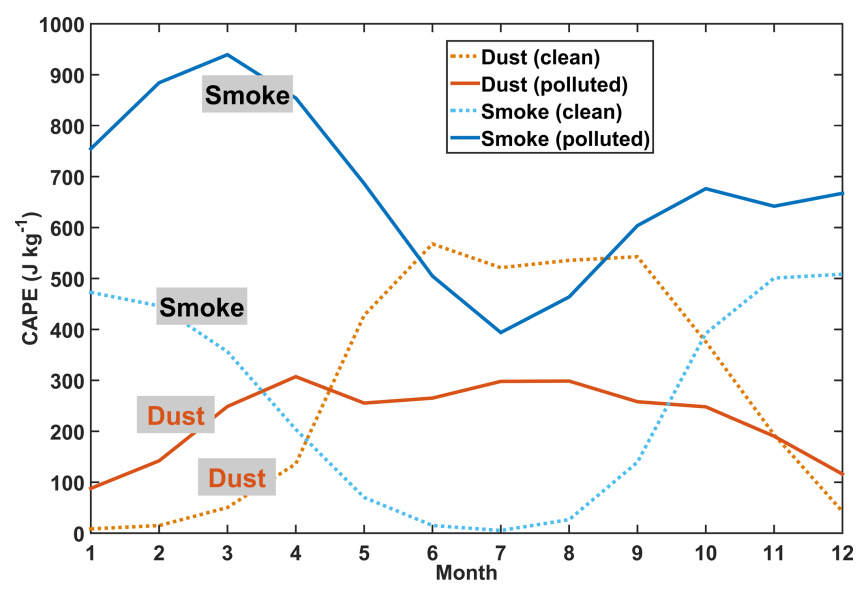

Figure 3. Seasonal variations in CAPE under relatively clean and polluted conditions in the dust- and smoke-dominant regions. Clean (polluted) cases are defined as those CAPE values corresponding to the lowest (highest) third of the aerosol optical depth (AOD) range $(\mathrm{AOD} \in(0,1))$.
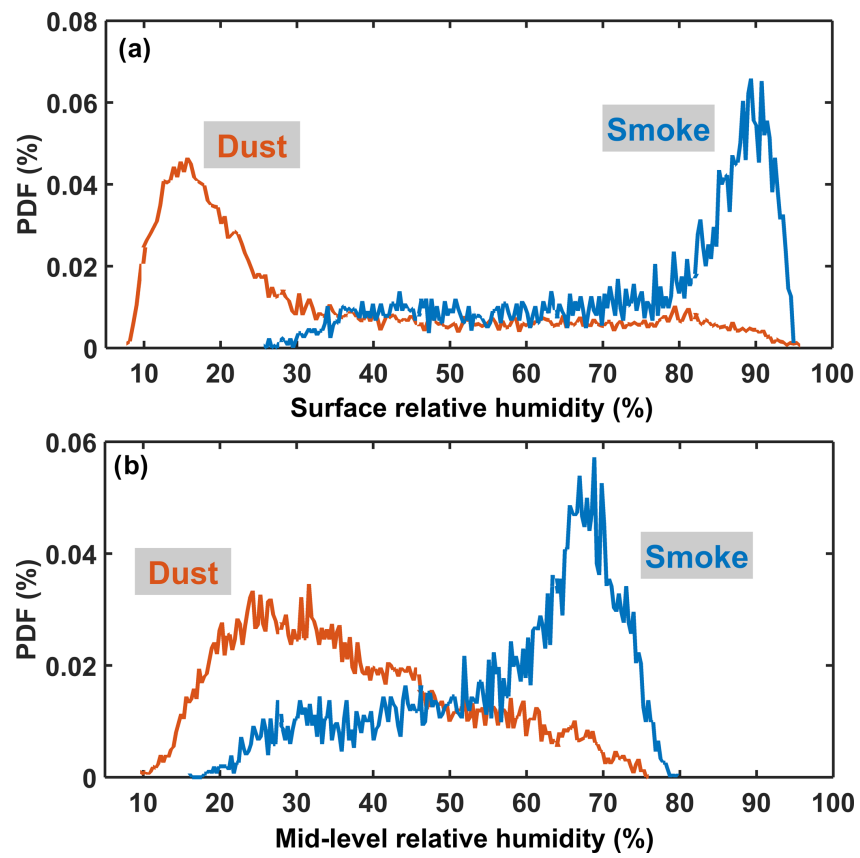

Figure 4. The probability density function (PDF) of (a) surface and (b) mid-level relative humidity in the dust- and smoke-dominant regions.

mid-level relative humidity and CAPE are conducive to the development of intense convection and that the lightning occurrence is associated with high-level divergence. One thing to notice is the shape of the density traces in Fig. 5f. The bimodal distribution indicates that small to moderate high-level divergence may be due to clear-sky or in-cloud atmospheric movement with a small updraft velocity that does not produce lightning. Large divergence usually characterizes the strong upward movement closely associated with lightning activity. Inverse correlations between the lightning flash rate and sea level pressure and between the lightning flash rate and wind shear are seen in Fig. 5a and e. Figure 5b shows a weak, positive correlation between the lightning flash rate and potential temperature. The small correlation coefficients of the regressions between the lightning flash rate and sea level pressure, wind shear, and potential temperature suggest little correlation between these variables and the lightning flash rate.

Figure 6 shows the linear correlations between the lightning flash rate and the six dynamic-thermodynamic variables associated with strong convection for the smoke-dominant region. Mid-level relative humidity, CAPE, and divergence are positively correlated with the occurrence of lightning as opposed to sea level pressure, potential temperature, and wind shear, which are negatively correlated with the lightning flash rate. In particular, Fig. 6a, c, d, and $\mathrm{f}$ show that CAPE, mid-level relative humidity, divergence, and sea level pressure are significantly correlated with the lightning flash rate $(|R|>0.75, p<0.05$; in order of the correlation strength), suggesting that these four variables may be the major factors modulating changes in the lightning flash rate. By comparison, a moderate linear relationship exists between the lightning flash rate and potential temperature $(R=-0.47)$, which is also the case for the relationship between the lightning flash rate and wind shear ( $R=-0.08$ ), suggesting their minor effects on the lightning flash rate (Fig. 6b and e). Simulations done by Weisman and Klemp (1982) show that weak, moderate, and high wind shear produces short-lived single cells, secondary development, and split storms, respectively. The coarse time resolution may be why no significant correlation is found between shear and the lightning flash rate. Note that the correlation coefficients obtained here can only describe the possible dependencies between the lightning flash rate and dynamicthermodynamic variables and cannot imply causal relationships.

To provide a visual comparison of the dust- and smokedominant regions, we show the spatial distributions of the correlation coefficients of the regressions between the lightning flash rate and dynamic-thermodynamic variables. Figure 7 shows that lightning flash rates are well correlated with mid-level relative humidity, CAPE, and divergence throughout both the dust- and smoke-dominant regions (most parts $R>0.6$ ), while for other variables, the correlations vary from region to region. In particular, the correlations between the lightning flash rate and sea level pressure (positive), potential temperature (negative), and wind shear (positive) near the Earth's Equator are distinctly different from those over other regions. We infer that this is because the hot and humid environment year-round favors deep convection. Wind shear helps organize mesoscale convection in moist deep convection which produces more lightning. Regarding potential temperature, rich precipitation helps cool the sur- 

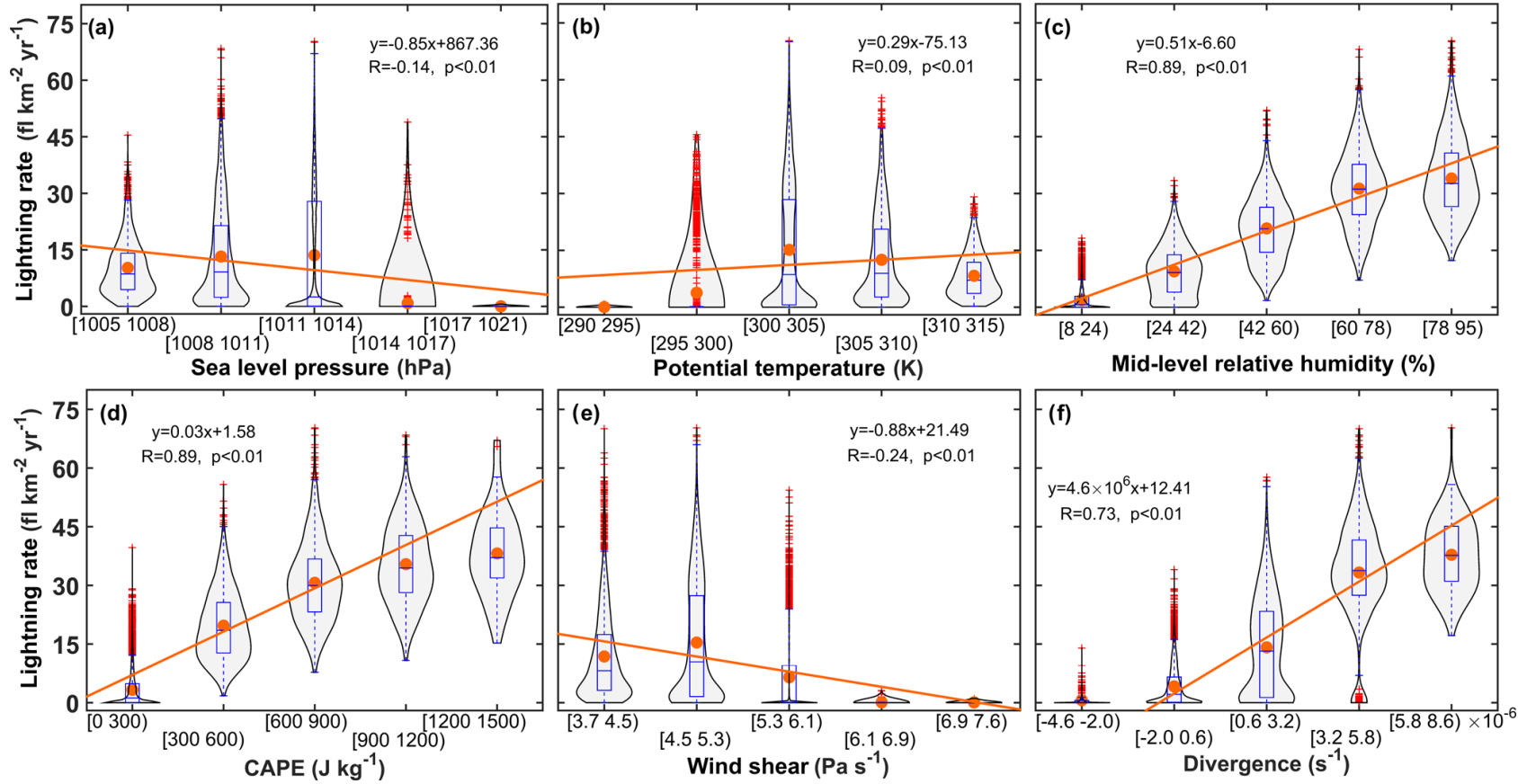

Figure 5. Violin plots of lightning dispersion showing the relationship between the lightning flash rate and six dynamic-thermodynamic variables: (a) sea level pressure, (b) potential temperature, (c) mid-level relative humidity, (d) convective available potential energy (CAPE), (e) vertical wind shear, and (f) $200 \mathrm{hPa}$ divergence in the dust-dominant region. The five bins are equally spaced. Box plots represent the interquartile range (the distance between the bottom and the top of the box), the median (the band inside the box), the $95 \%$ confidence interval (whiskers above and below the box), the maximum (the end of the whisker above), the minimum (the end of the whisker below), and the mean (orange dot) in each bin. The plus signs represent outliers. On each side of the black line is the kernel estimation showing the distribution shape of the data. The estimate is based on a normal kernel function and is evaluated at 100 equally spaced points. Wider sections of the violin plot represent a high probability that members of the population will take on the given value; the skinnier sections represent a lower probability. The equations describe the linear correlations between the lightning flash rate and the dynamic-thermodynamic variables. Pearson correlation coefficients $(R), p$ values, and the linear regression lines (in orange) are also shown. Data used here are from every grid square $\left(2.5^{\circ} \times 2.5^{\circ}\right)$ through the whole year from 2003 to 2013 . Dynamic-thermodynamic variables are processed using 3-month running mean filters to match with lightning data.

face, which causes the negative correlation between the lightning flash rate and potential temperature. Different from the frontal system-dominant strong convection in the midlatitudes, thermal convection more likely occurs in the tropics with a much smaller air pressure change. The frequent precipitation may also help create low- and high-pressure centers on the ground. These two points may lead to the positive correlation between the lightning flash rate and sea level pressure. However, partial correlation analyses show that only CAPE and mid-level relative humidity are the top two factors affecting lightning activity (Fig. 8).

\subsection{Contrast in the response of the lightning flash rate to dust and smoke aerosols}

Aerosols can modulate lightning activity by participating in radiative and microphysical processes. Besides the finding that the peak time for lightning under polluted conditions is delayed by about $1 \mathrm{~h}$ or so (see Fig. 2), more informative and revealing features of the impact of aerosols on lightning are presented in Fig. 9. The scatterplot and two curves (100point and 50-point running means are applied thrice to the mean values of lightning flash rate in each 30 -sample bin for the dust-dominant region and the smoke-dominant region, respectively) show that lightning activity is much more intense in the smoke-dominant region located in the ITCZ where the air is hot and humid regardless of aerosol loading. By contrast, the dust-dominant region is much drier, making it difficult to produce intense convection and lightning. The response of the lightning flash rate to AOD is shaped like a boomerang (Koren et al., 2008) with a turning point around $\mathrm{AOD}=0.3$, and the turning point in the dust-dominant region is slightly ahead of that in the smoke-dominant region. This is mainly because fewer aerosols are needed to produce small droplets likely to evaporate in the drier dust-dominant region so the optimal AOD will be lower. We deduce that the $\mathrm{CCN}$ concentration is more closely allied with the cloud microphysics pertaining to lightning based on the equation fitted by Andreae (2009). The turning point of the CCN concentration at a supersaturation of $0.4 \%$ is $\sim 1600 \mathrm{~cm}^{-3}$ (see 

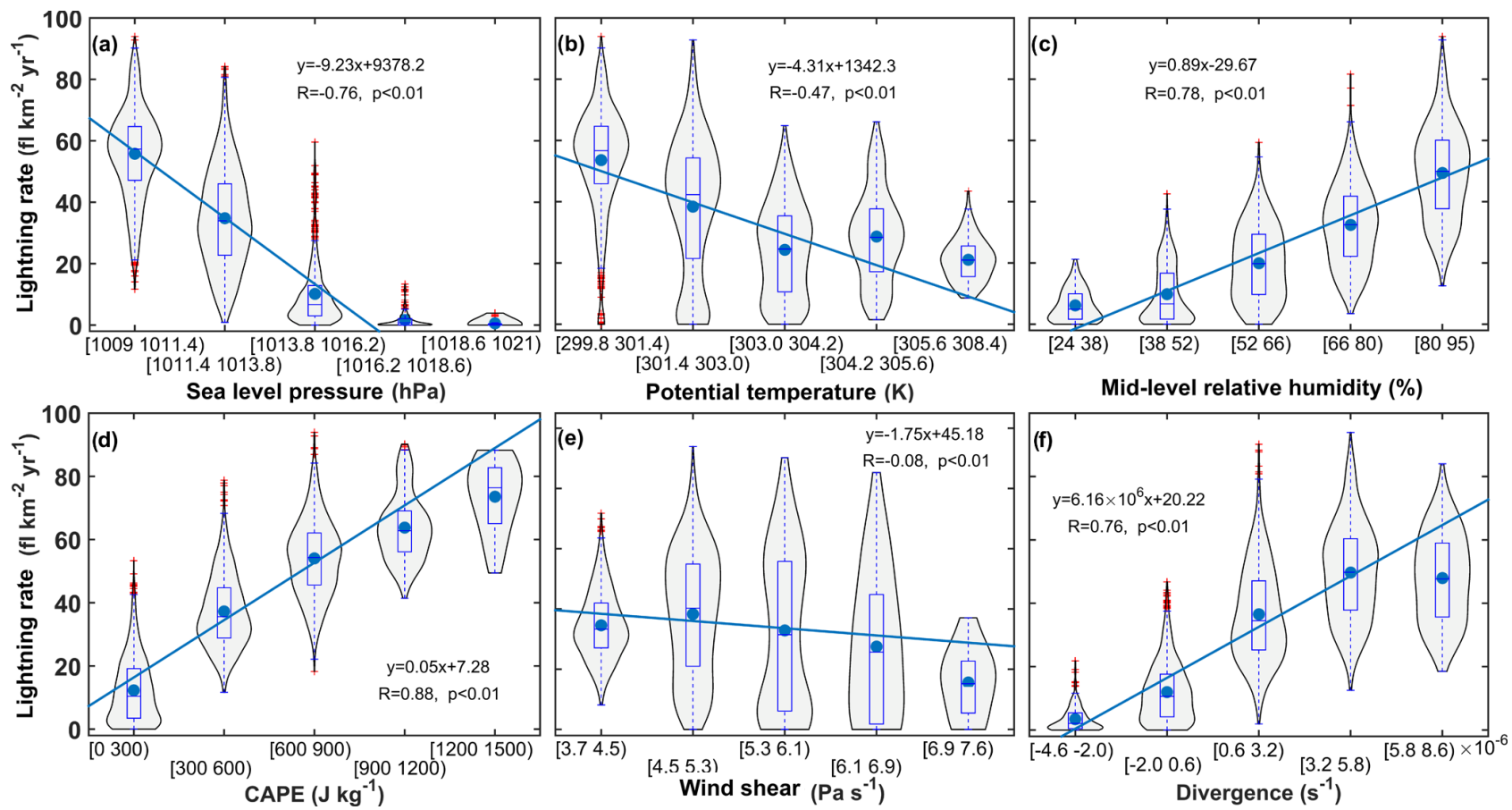

Figure 6. Same as in Fig. 5, but for the smoke-dominant region. Mean values are represented by blue dots, and linear regression lines are shown in blue.
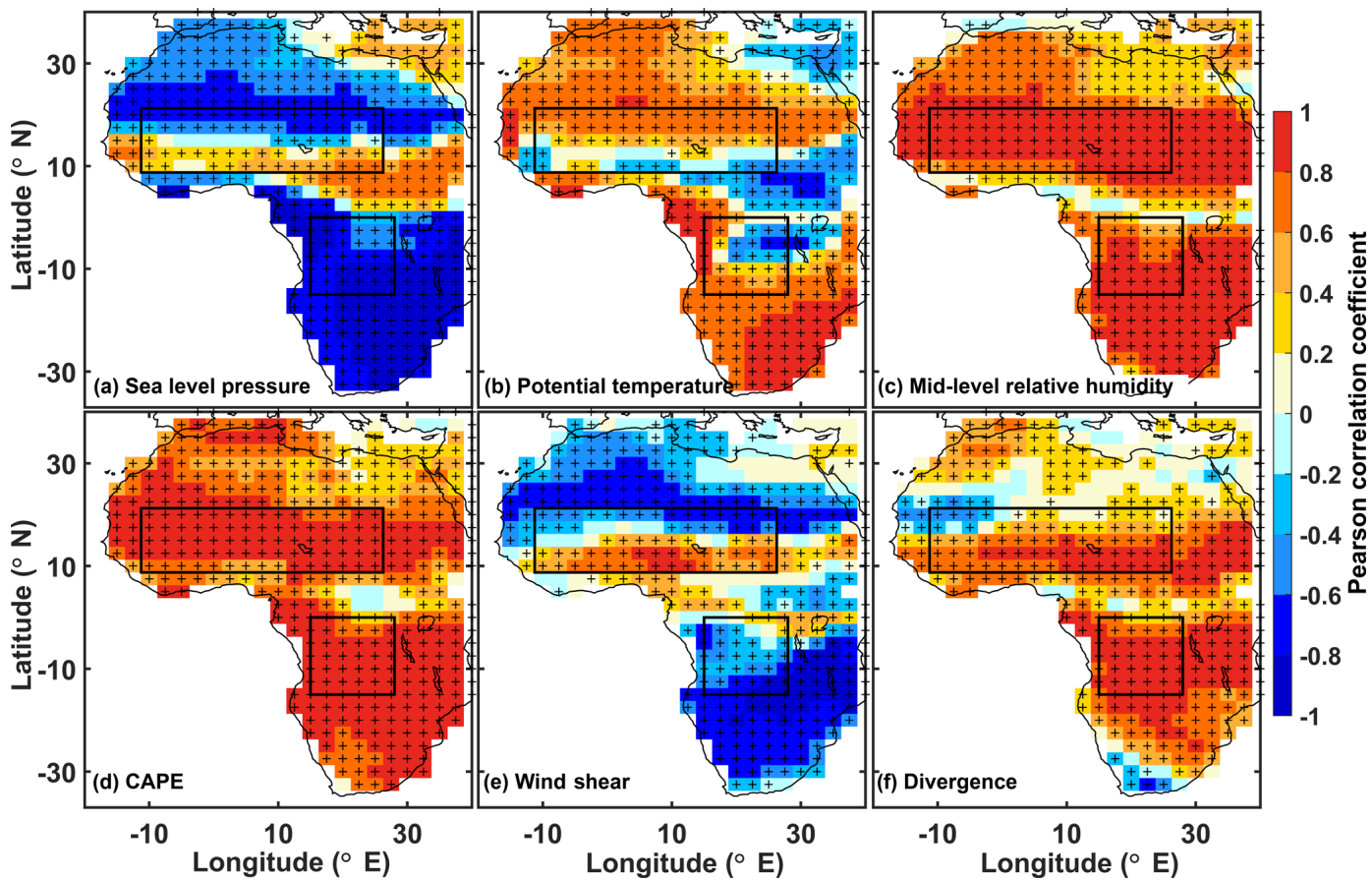

Figure 7. Maps of Pearson correlation coefficients between the lightning flash rate and (a) sea level pressure, (b) potential temperature, (c) mid-level relative humidity, (d) mean convective available potential energy (CAPE), (e) vertical wind shear, and (f) $200 \mathrm{hPa}$ divergence over Africa at a spatial resolution of $2.5^{\circ} \times 2.5^{\circ}$ from 2003 to 2013 (including all seasons). In each grid, 132 samples are used to calculate the correlation coefficient. For each sample, variables are processed using 3-month smoothing averages. The black rectangles outline the dust- and smoke-dominant regions (see Fig. 2, left panel). Plus signs denote those grids that pass the significance test of 0.05 . 


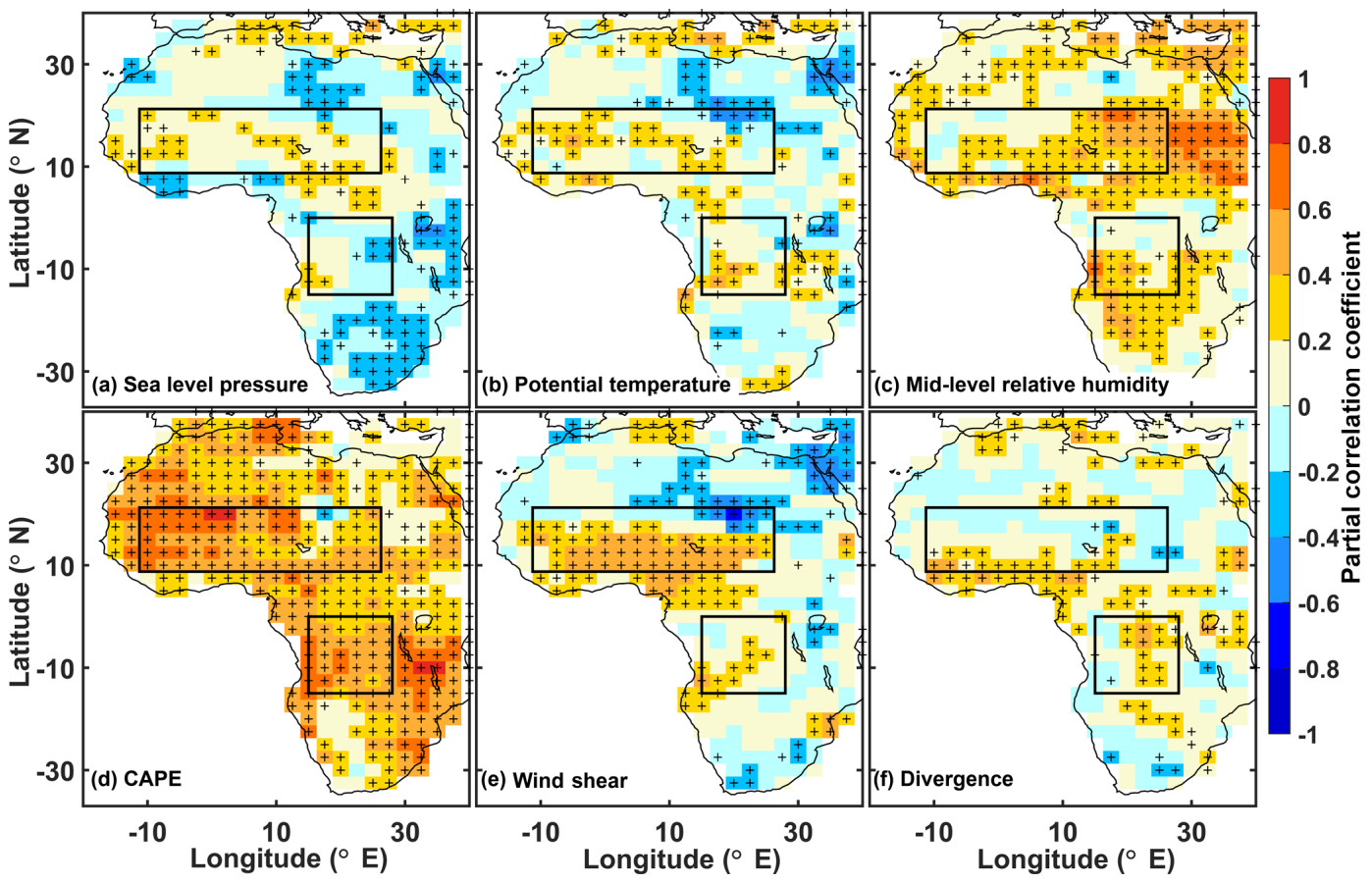

Figure 8. Same as in Fig. 7, but for the partial correlation coefficients.

Fig. S3 in the Supplement), which falls within the range of $1000-2000 \mathrm{~cm}^{-3}$ (Mansell and Ziegler, 2013) and is close to $1200 \mathrm{~cm}^{-3}$ (Rosenfeld et al., 2008). Figure 9 is separated into three zones (green, grey, red) to show the dominant roles of the aerosol microphysical effect and the aerosol radiative effect. In the green zone, the lightning flash rate increases sharply with increasing aerosol loading in both the dust- and smoke-dominant regions. Data are clustered around the regression lines tightly, and the lightning flash rate is strongly and positively correlated with AOD, implying that aerosol-cloud interactions (ACI) play a dominant role in lightning activity. However, as AOD approaches the turning point (the grey zone), data become more scattered and the trend is reversed likely because of the joint impact of the aerosol microphysical effect and the aerosol radiative effect that have opposite signs of compatible magnitude (Koren et al., 2008; Rosenfeld et al., 2008). However, other dynamicthermodynamic effects cannot be ruled out. In the red zone, the response of the lightning flash rate to aerosol loading is different between dust and smoke aerosols. The lightning flash rate seems to be saturated in the smoke-dominant region but is strongly suppressed in the dust-dominant region. This is likely associated with the differences in both aerosol properties and dynamics-thermodynamics which are coupled to jointly affect lightning. The different dynamic and thermodynamic conditions between the two regions may play important roles:

1. The drier the mid-level atmosphere, the more likely that there is evaporation of cloud droplets that are smaller under heavily polluted conditions. The aerosolmicrophysical-effect-induced evaporation tends to suppress the development of clouds and inhibits lightning activity in combination with the aerosol radiative effect which causes surface cooling and leads to an increase in atmosphere stability. Together, the two factors are compounded, leading to a sharp decline in the lightning rate under heavy dusty conditions in the dust-dominant region.

2. However, clouds in the moister region of central Africa are less susceptible to evaporation and suppression. The strongly absorbing smoke aerosols also heat up the aerosol layers (usually below deep convective clouds that produce lightning), destabilizing the atmosphere above and thus dampening the suppression effect of the aerosol-radiation interactions (ARI). The development of convection and associated lightning is thus sustained.

\subsection{Environmental dependence of the aerosol effect}

To further clarify the joint influences of dynamics, thermodynamics, and aerosols on lightning activity, the distribution of the lightning flash rate with AOD and the top two influential thermodynamic variables, i.e., mid-level relative humidity and CAPE (based on the results in Figs. 5-8), are examined in Fig. 10. Lightning flash rates are classified into 100 discrete cells by 10 decile bins of a horizontal axis variable and 10 decile bins of a vertical axis variable (AOD-CAPE, AOD-mid-level relative humidity, and 


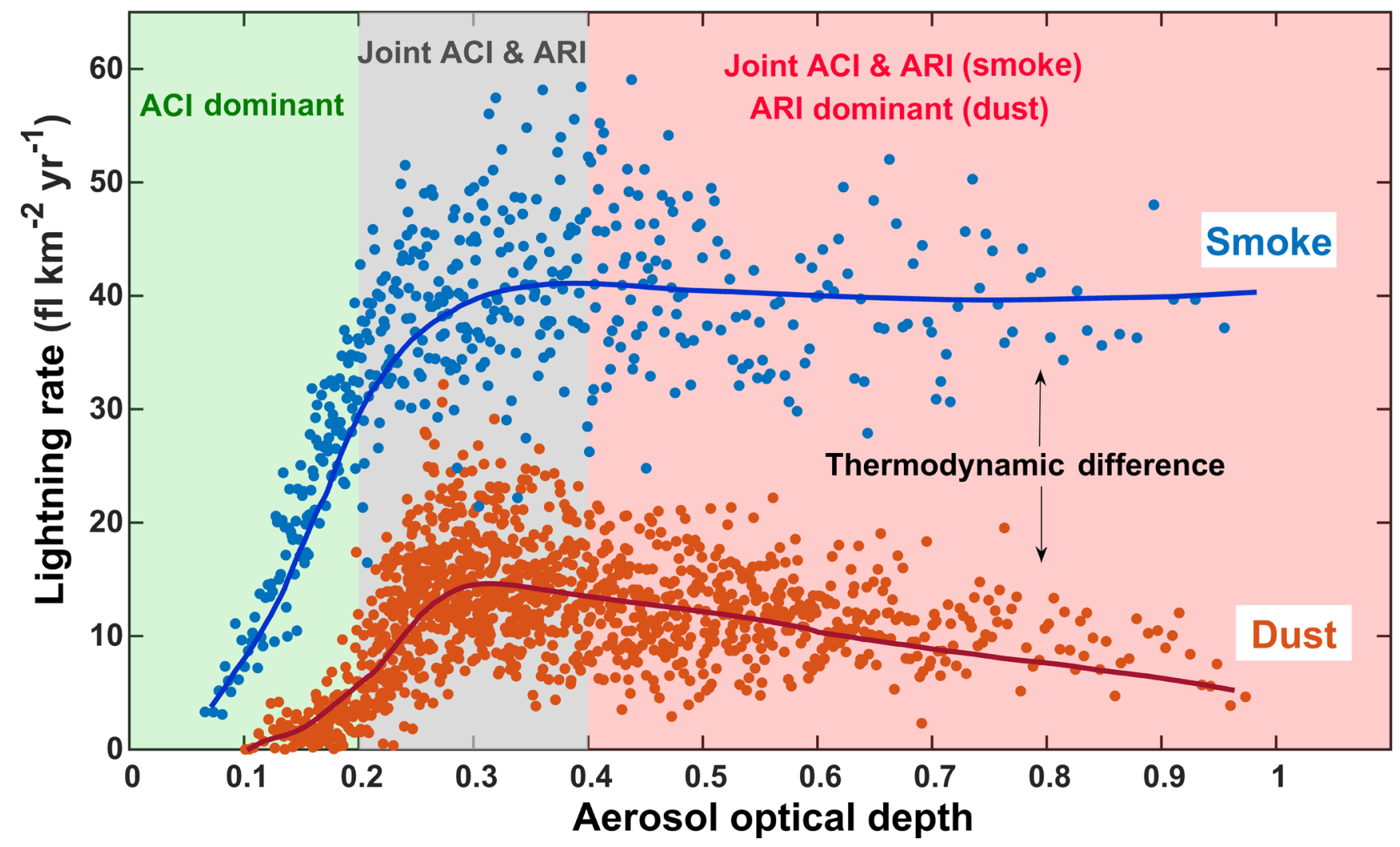

Figure 9. Lightning flash rate as a function of aerosol optical depth (AOD) in the dust- (orange points) and smoke-dominant regions (blue points). Note that all data pairs (i.e., a 3-month mean lightning rate and a 3-month mean AOD) are first ordered by AOD from small to large. Mean values of both AOD and lightning flash rate in each 10-sample bin are then calculated to reduce the uncertainty caused by the large dispersion of data. The two curves are created by applying a 100-point moving average (50-point) thrice to the mean values of lightning flash rate in each 30-sample bin for the dust-dominant (smoke-dominant) region. Note that data used here are for the entire AOD range but only shown for the range AOD $\in(0,1)$. Turning points in the boomerang shapes are around AOD $=0.3$. Aerosol-cloud interactions $(\mathrm{ACI})$ play a dominant role in lightning activity under relatively clean conditions (green zone). As AOD exceeds 0.3 , both ACI and aerosol-radiation interaction (ARI) effects come into play with different magnitudes. For dust aerosols, ACI and ARI have the same effect of suppressing convection in the dry environment favorable for evaporating cloud droplets. The moist environment of central Africa strengthens aerosol invigoration that offsets the suppression due to ARI, leading to a nearly flat line in the grey and red zones.

CAPE-mid-level relative humidity), which ensures approximately equal sample sizes among the cells. The mean values are calculated in each cell. Looking at the CAPE bins, the lightning flash rate generally increases with increasing AOD under relatively clean conditions but decreases after the turning point near $\mathrm{AOD}=0.3$ in both regions (Fig. 10a and d). When AOD is fixed, the lightning flash rate monotonically increases with CAPE. Irrespective of aerosol loading and region, lightning rarely occurs when CAPE is less than $100 \mathrm{~J} \mathrm{~kg}^{-1}$. Half of the CAPE data in the dust-dominant region falls below this value. Systematically higher CAPE in the smoke-dominant region plays an important role in inducing more intense lightning activity than in the dust-dominant region. However, the lightning flash rates in the dust- and smoke-dominant regions respond to mid-level relative humidity in different ways when AOD is fixed (Fig. 10b and e). In the dust-dominant region, the lightning flash rate increases monotonically as mid-level relative humidity increases for all AOD, but changes little as AOD increases in each relative humidity bin. This suggests that, apart from CAPE, relative humidity is another restraint on lightning activity in the dust-dominant region. In the smoke-dominant region, large lightning flash rates appear in the environment of moderate mid-level relative humidity and high aerosol loading. When relative humidity is fixed, the response of the lightning flash rate to AOD also shows a turning point in AOD around AOD $=0.3$. Beyond this value, the lightning flash rate remains high. When looking into the common roles of relative humidity and CAPE on lightning, the data distribution along the diagonal shows that mid-level relative humidity is highly correlated with CAPE and that they affect lightning activity in the same direction. In general, intense lightning activity occurs under high mid-level relative humidity $(>40 \%)$ and high CAPE $\left(>100 \mathrm{~J} \mathrm{~kg}^{-1}\right)$ conditions in the dust-dominant 


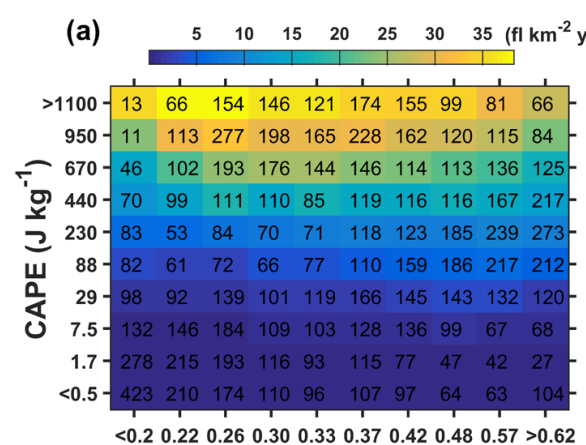

(d)

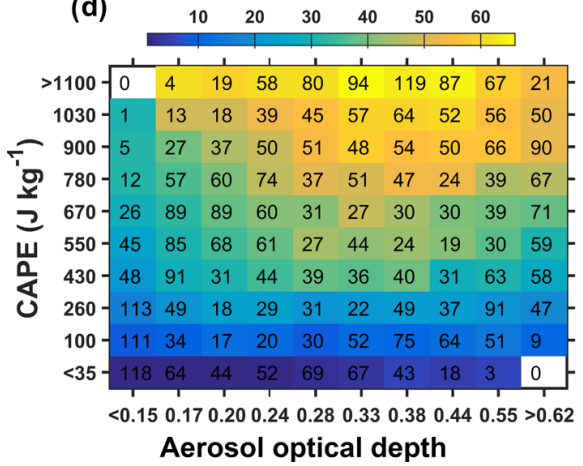

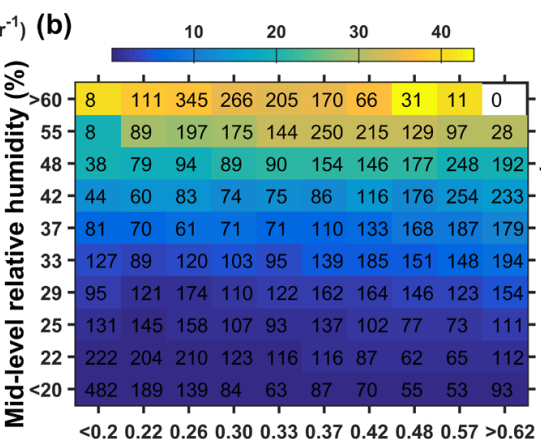

(e)

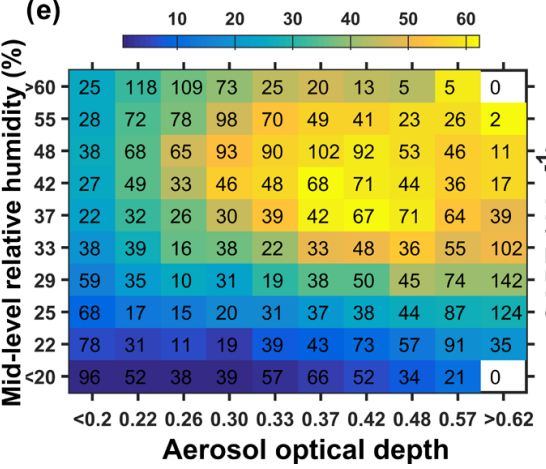

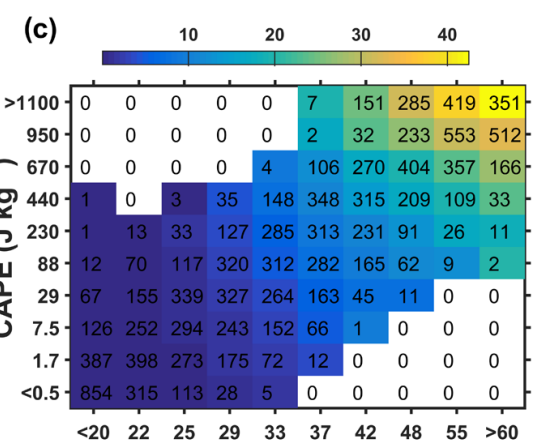

(f)

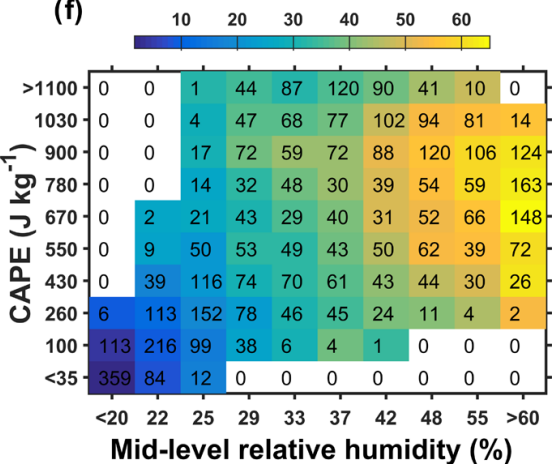

Figure 10. Joint dependence of the lightning flash rate on CAPE, mid-level relative humidity, and aerosol optical depth in the dust- (a-c) and smoke-dominant (d-f) regions. The bold number in each cell indicates the number of samples in the cell. The color bar denotes the number of lightning flash rates averaged in each cell.

region. In the smoke-dominant region, high CAPE and high mid-level relative humidity are still conducive to lightning production, but the data variance is larger, suggesting that the correlation involving mid-level relative humidity and CAPE is not as high as in the dust-dominant region, and the dependence on relative humidity is reduced.

As shown in Figs. 2, 9, and 10, differences in the lightning response to aerosols in the dust- and smoke-dominant regions may also be attributed to different dynamic-thermodynamic conditions. To isolate the signal attributed to aerosol loading from that attributed to environmental forcing, lightning flash rates are categorized according to six dynamicthermodynamic variables (sea level pressure, potential temperature, mid-level relative humidity, CAPE, wind shear, and divergence). Figure 11 shows the differences in lightning flash rate between polluted and clean conditions (polluted minus clean datasets) as a function of these six variables. In general, lightning flash rates are greater for all these dynamic-thermodynamic variables under polluted conditions compared with clean conditions in both the dust- and smoke-dominant regions. Lightning enhancement under polluted conditions is highly significant ( $>99 \%$ ) based on the Student's $t$ test. The differences in lightning flash rates between polluted and clean conditions are smaller in the dustdominant region than in the smoke-dominant region. Note that in the dust-dominant region, when sea level pressure decreases and potential temperature increases, differences in the lightning flash rate (polluted minus clean datasets) become larger. This suggests that under conductive conditions (such as a thermal depression which is likely the main synoptic system introducing lightning activity in this region), aerosols are more likely to participate in cloud microphysics and convective development, thus modulating lightning activity.

\subsection{Relative roles of dynamics-thermodynamics and AOD on the lightning flash rate}

The response of the lightning flash rate to changes in AOD may indicate an aerosol effect on lightning activity, but it can also be the result of dynamics or thermodynamics impacting aerosol loadings and the cloud microphysical process that is closely associated with lightning production. To further explore this complex process, the correlations between aerosollightning rate, dynamic-thermodynamic variables-lightning rate, and aerosol-dynamic-thermodynamic variables were examined before and after the turning point $(\mathrm{AOD}=0.3$, see Fig. 9). Results are shown in Fig. 12 (correlation coefficients are listed in Table S2 in the Supplement).

Under clean conditions $(\mathrm{AOD}<0.3)$ in the dust-dominant region, all dynamic-thermodynamic variables and AOD show good correlations with the lightning flash rate $(|R|>0.5)$. Considering the interaction between aerosols and dynamics-thermodynamics, the correlation coefficients be- 

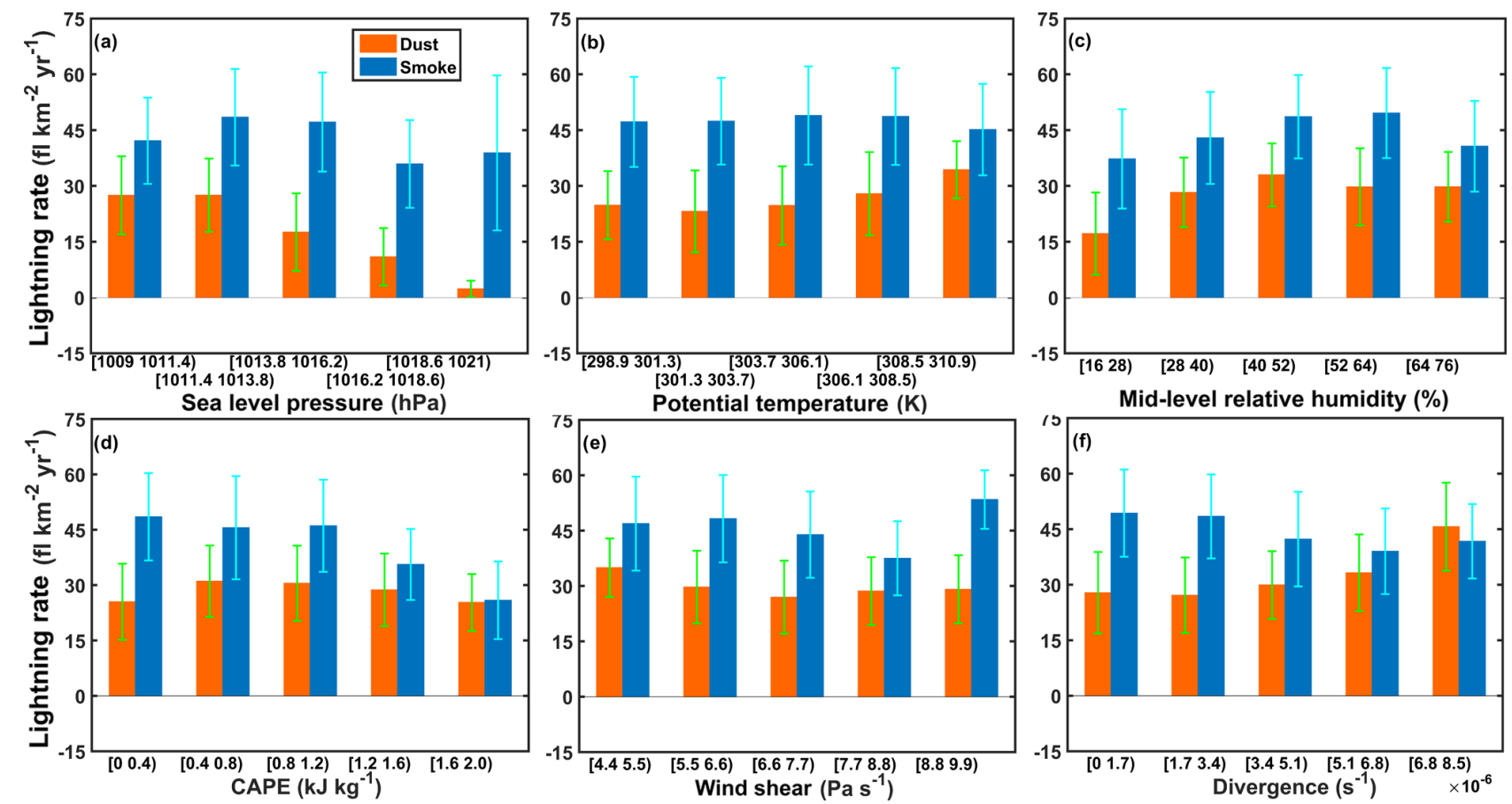

Figure 11. Differences (polluted minus clean subsets of data) in lightning flash rate as a function of (a) sea level pressure, (b) potential temperature, (c) mid-level relative humidity, (d) convective available potential energy (CAPE), (e) vertical wind shear, and (f) $200 \mathrm{hPa}$ divergence in the dust- (in orange) and smoke-dominant regions (in blue). Note that the top third of aerosol optical depth (AOD) values $(\mathrm{AOD} \in(0,1))$ is labeled as polluted, and the bottom third is labeled as clean. Vertical error bars represent 1 standard deviation.

tween AOD and the six dynamic-thermodynamic variables were calculated. Results show strong, positive correlations between AOD and mid-level relative humidity, CAPE, divergence, and potential temperature $(R>0.6)$ and a negative correlation between AOD and sea level pressure and wind shear (in order of correlation strength). To investigate the relative roles of these variables (AOD and the six dynamicthermodynamic variables), we carry out partial correlation analyses between the lightning flash rate and any of its influential factors while constraining all the others. We then establish standardized multiple regression equations where the coefficients of these equations represent the relative importance of each factor. After the common effects are constrained, the partial correlation coefficients are much smaller than the Pearson correlation coefficients, and the correlations between the lightning flash rate and sea level pressure, potential temperature, and AOD are no longer significant. The weak partial correlation of the AOD-lightning-flash-rate relationship, the high Pearson correlation of the AOD-CAPE relationship, and the high partial correlation of the CAPElightning-flash-rate relationship all suggest that the lightning flash rate does not respond much to dust aerosols directly, but dust can affect convection and lightning activity through modulation of the thermodynamic variables involved in ACI. From these analyses, the top three factors are found to be mid-level relative humidity, CAPE, and divergence for the dust-dominant region under relatively clean conditions. For the clean smoke-dominant region, analyses show strong positive correlations between the lightning flash rate and CAPE, $\mathrm{AOD}$, and divergence $(|R|>0.7)$; a strong negative correlation between the lightning flash rate and sea level pressure $(R=-0.94)$; and weak negative correlations between the lightning flash rate and potential temperature and wind shear $(|R|<0.4)$. The main interplay is between AOD and sea level pressure and CAPE $(|R|>0.75)$. The partial correlation coefficients and the coefficients of the standardized multiple regression equations reveal the top three factors: CAPE, AOD, and mid-level relative humidity $(R>0.35)$. Different from relative humidity as the top restraint factor in the dustdominant region, here it plays a smaller role in the humid environment. AOD also becomes more important in this region. In both regions, aerosols correlate well with CAPE $(R>0.75)$ under clean conditions (AOD $<0.3)$, which suggests that aerosols might participate in cloud microphysical processes: more aerosols acting as $\mathrm{CCN}$ leads to a narrower cloud droplet size spectrum, delays the warm-rain process, and allows more liquid water to ascend higher into the mixed-phase cloud, thus releasing more latent heat, modulating environmental variables (such as increasing temperature, updrafts, and CAPE in and above clouds), and producing a more unstable atmosphere conducive to convective development. The aerosol invigoration effect may play the key role during this stage $(\mathrm{AOD}<0.3)$. The same directions of the impacts of aerosols and thermodynamics such as CAPE on the 


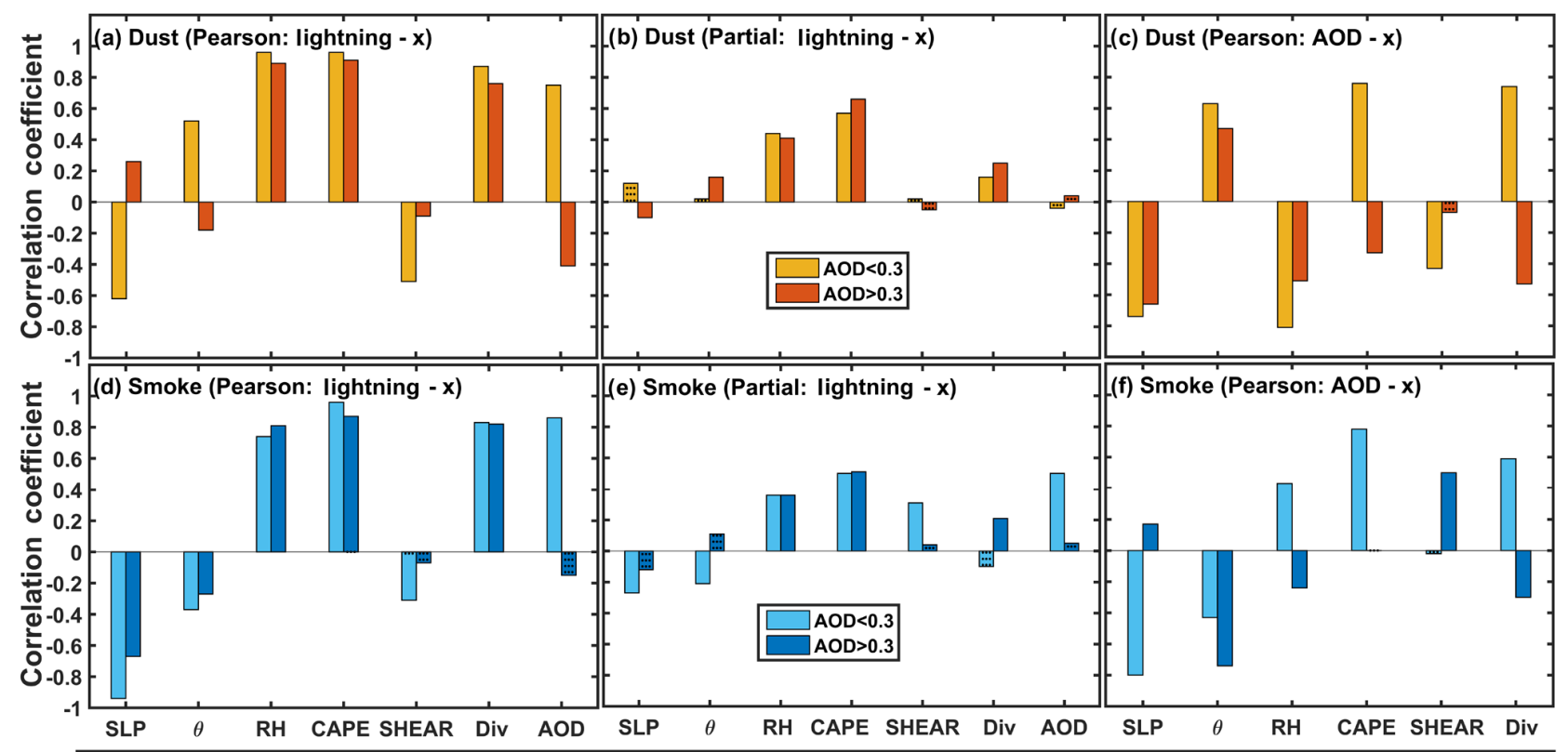

\begin{tabular}{|l}
\hline (g) Standardized multiple regression equation : $y$ (Lightning), $x_{1}(S L P), x_{2}(\theta), x_{3}(R H), x_{4}(C A P E), x_{5}\left(\right.$ SHEAR), $x_{6}$ (Div), $x_{7}$ (AOD) \\
\begin{tabular}{rlll} 
ROI_1 (AOD $<0.3):$ & $y=0.07 x_{1}+0.08 x_{2}+0.49 x_{3}+0.49 x_{4}+0.01 x_{5}+0.09 x_{6}-0.02 x_{7}-1.52 \times 10^{-14}$ & $\left(R_{M}=0.96\right)$ \\
ROI_1 (AOD>0.3): & $y=0.11 x_{1}+0.15 x_{2}+0.34 x_{3}+0.54 x_{4}-0.02 x_{5}+0.15 x_{6}+0.02 x_{7}-5.44 \times 10^{-14}$ & $\left(R_{M}=0.91\right)$ \\
ROI_2 (AOD<0.3): & $y=-0.21 x_{1}-0.06 x_{2}+0.32 x_{3}+0.42 x_{4}+0.13 x_{5}-0.08 x_{6}+0.25 x_{7}-5.28 \times 10^{-14}$ & $\left(R_{M}=0.96\right)$ \\
ROI_2 (AOD>0.3): & $y=-0.07 x_{1}+0.09 x_{2}+0.31 x_{3}+0.51 x_{4}+0.02 x_{5}+0.17 x_{6}+0.04 x_{7}-1.02 \times 10^{-14}$ & $\left(R_{M}=0.88\right)$ \\
\hline
\end{tabular}
\end{tabular}

Figure 12. (a, d) Pearson correlation coefficients of the linear regression relationships between the lightning flash rate and the six dynamicthermodynamic variables and aerosol optical depth (AOD). (b, e) Partial correlation coefficients of the relationships between the lightning flash rate and any influential factor (AOD or dynamic-thermodynamic variables) with the others as control variables. (c, f) Pearson correlation coefficients of the linear regression relationships between AOD and any given dynamic-thermodynamic variable. The top panels are for the dust-dominant region, and the bottom panels are for the smoke-dominant region. Those bars with dots on them signify success of the statistical significance test at the $95 \%$ confidence level. Also shown are standardized multiple regression equations of the lightning flash rate (y) onto the six dynamic-thermodynamic variables $\left(x_{1}-x_{6}\right)$ and AOD $\left(x_{7}\right)$ and standardized multiple correlation coefficients $\left(R_{\mathrm{M}}\right)$. The six dynamic-thermodynamic variables are sea level pressure (SLP, $\left.x_{1}\right)$, potential temperature $\left(\theta, x_{2}\right)$, mid-level relative humidity (RH, $\left.x_{3}\right)$, mean convective available potential energy (CAPE, $x_{4}$ ), vertical wind shear (SHEAR, $x_{5}$ ), and 200 hPa divergence (Div, $x_{6}$ ).

lightning flash rate may be the reason for the tightly clustered distribution under clean conditions seen in Fig. 9.

Under polluted conditions, CAPE and mid-level relative humidity are still of paramount importance for lightning activity (Pearson: $R>0.8$; partial: $R>0.35$ ), but the correlation between aerosols and dynamics-thermodynamics is weakened. This weak connection between aerosols and dynamicsthermodynamics results in a large dispersion of lightning flash rates under polluted conditions in both regions. The most important finding appears to be the negative correlation between AOD and CAPE $(R=-0.51)$ and between AOD and mid-level relative humidity $(R=-0.33)$ in the dustdominant region. This suggests two things: (1) drier environments are more favorable for dust emission; and (2) drier mid-level environments produce a more stable atmosphere and rapid evaporation of the condensate, leading to the suppression of convection and lightning. In the smoke-dominant region, AOD is negatively correlated with mid-level relative humidity $(R=-0.24)$, which suggests the similar role of drier environments in producing more smoke aerosols. The negative correlation between AOD and potential temperature $(R=-0.74)$ reflects the surface cooling that is caused by the radiative effect. No significant correlation is found between AOD and CAPE $(R=0, p>0.05)$, which may imply that the radiative effect and the microphysical effect are comparable under heavy-smoke aerosol loading conditions.

\section{Conclusions}

Depending on specific environmental conditions, aerosols are able to invigorate or suppress convection-induced lightning activity. This has been noted in previous case-based studies. This study attempts to (1) answer a key question of whether aerosol effects on lightning are of long-term climate significance, (2) disentangle the complex influences of aerosols and dynamics-thermodynamics on lightning activity and their mutual dependencies, and (3) investigate different roles played by different types of aerosols (dust ver- 
sus smoke) on lightning. Here, dynamics and thermodynamics are characterized by six variables: sea level pressure, potential temperature, mid-level relative humidity, convective available potential energy (CAPE), vertical wind shear, and $200 \mathrm{hPa}$ divergence. The 11 years (2003-2013) of coincident data are used, including lightning data from the TRMM LIS, aerosol optical depth (AOD) from the Aqua MODIS, and dynamic-thermodynamic variables from the ECMWF ERAInterim reanalysis. Climatological features of the diurnal and seasonal variations in lightning flash rate show a peak in the afternoon and during the local summer, respectively, which suggests the dominant role of thermodynamics, while differences in lightning flash rate under relatively clean and polluted conditions signify the potential influences of aerosols. In general, differences in lightning flash rates are larger in moist central Africa dominated by biomass burning than in dry northern Africa with much dust. Despite the complex and diverse climatic conditions, the response of the lightning flash rate to dust and smoke aerosols has a boomerang shape with a turning point at $\mathrm{AOD} \approx 0.3$. As $\mathrm{AOD}$ increases towards the threshold, the flash rate first increases sharply with increasing AOD for both the dust and biomass-burning regions. As AOD exceeds the threshold, the response turns negative and is more pronounced for dust aerosols than for smoke aerosols. Grossly speaking, such a pattern echoes the joint influences of the aerosol microphysical effect and the aerosol radiative effect, with the former and latter being more significant under low-AOD and high-AOD conditions, respectively. Around the turning point, the two effects are comparable.

We performed a correlation analysis and a standardized multiple regression analysis in an attempt to quantify the relative roles of AOD and dynamic-thermodynamic factors in modulating lightning activity. Under relatively clean conditions $(\mathrm{AOD}<0.3)$, standardized multiple regression coefficients of dynamics, thermodynamics, and AOD on the lightning flash rate in both regions have $R_{\mathrm{M}}^{2} \geq 0.92$, with midlevel relative humidity and CAPE being the top two determinant factors. The contributions of relative humidity and CAPE are comparable in the dust-dominant region and less so in the smoke-dominant region. The impact of AOD on lightning activity is likely to be exerted through a cloud microphysical effect that may modulate the dynamics and thermodynamics. Under smoky conditions (AOD $>0.3$ ), $R_{\mathrm{M}}^{2}$ for the standardized multiple regression equation diminishes to 0.77 , with a strong negative correlation with potential temperature $(R=-0.74)$, a weak negative correlation with mid-level relative humidity, and no correlation with CAPE $(R=0)$. Note that aerosols cool the surface and warm the mid-level atmosphere through the radiative effect which may be less than (for $\mathrm{AOD}<0.3$ ), more than $(\mathrm{AOD}>0.3$ ), or equal to $(\mathrm{AOD}=0.3)$ the aerosol microphysical effect. Under dusty conditions (AOD $>0.3$ ), the standardized multiple regression equation has a higher $R_{\mathrm{M}}^{2}(0.83)$, and the aerosol radiative effect plays a dominant role, possibly leading to a stable atmosphere and suppression of convection and lightning. Lightning flash rates in the dust- and smoke-dominant regions respond to AOD in different ways mainly because of the different humidity conditions. For the dust-dominant region, moisture is the maximum constraint. High CAPE, high mid-level relative humidity, and moderate aerosol loadings help to intensify lightning activity. For the smoke-dominant region, large values of CAPE, mid-level relative humidity, and AOD (up to 0.3) fuel lightning. The influences of other variables such as wind shear and convergence-divergence are insignificant from a climatological perspective. Based on observations alone, however, we cannot totally filter them out but can constrain the confounding effect of dynamics and thermodynamics on lightning activity. More insightful analyses based on a combination of state-of-the-art observations and convection-revolved model simulations are warranted in the future.

Data availability. Processed data in the study are available from the first author upon request (wangqianqian@mail.bnu.edu.cn). MODIS AOD data can be downloaded from https://ladsweb. modaps.eosdis.nasa.gov/search/ (last access: 31 August 2018). MERRAero data are from https://disc.sci.gsfc.nasa.gov/MERRA/ (last access: 31 August 2018), lightning data are from https:// ghrc.nsstc.nasa.gov/hydro/ (last access: 31 August 2018), and the ERA-Interim meteorological data are from http://apps.ecmwf.int/ datasets/data/interim-full-moda/ (last access: 31 August 2018).

\section{The Supplement related to this article is available online at https://doi.org/10.5194/acp-18-12797-2018- supplement.}

Author contributions. ZL and QW determined the main goal of this study; QW carried it out, analyzed the data and prepared the paper with contributions from all co-authors. JG provided ideas to extract aerosol information from other variables. Other co-authors participated in science discussions and article modification.

Competing interests. The authors declare that they have no conflict of interest.

Acknowledgements. We gratefully acknowledge the GES DISC, the NASA DAAC, and the ECMWF for providing aerosol information, lightning flash rate information, and dynamic-thermodynamic data via public access. We thank Tie Yuan, Hugh Christian, and Richard Orville for their assistance in using and analyzing TRMM LIS orbit data in the early stage of this study. We acknowledge $\mathrm{Wu}$ Zhang at Lanzhou University for his suggestions to improve the statistical methodology. This work was supported by the National Natural Science Foundation of China under grants 91544217 and 41771399, the Ministry of Science and Technology under grants 2017YFC1501702 and 2017YFC1501401, and the Chinese 
Academy of Meteorological Sciences (2017Z005).

Edited by: Jianping Huang

Reviewed by: Earle Williams and one anonymous referee

\section{References}

Altaratz, O., Koren, I., Yair, Y., and Price, C.: Lightning response to smoke from Amazonian fires, Geophys. Res. Lett., 37, L07801, https://doi.org/10.1029/2010GL042679, 2010.

Altaratz, O., Kucienska, B., Kostinski, A., Raga, G. B., and Koren, I.: Global association of aerosol with flash density of intense lightning, Environ. Res. Lett., 12, 114037, https://doi.org/10.1088/1748-9326/aa922b, 2017.

Andreae, M. O.: Biomass burning: its history, use, and distribution and its impact, in: Global Biomass Burning: Atmospheric, Climatic, and Biospheric Implications, MIT Press, Cambridge, MA, 3-21, 1991.

Andreae, M. O.: Correlation between cloud condensation nuclei concentration and aerosol optical thickness in remote and polluted regions, Atmos. Chem. Phys., 9, 543-556, https://doi.org/10.5194/acp-9-543-2009, 2009.

Bang, S. D. and Zipser, E. J.: Seeking reasons for the differences in size spectra of electrified storms over land and ocean, J. Geophys. Res.-Atmos., 121, 9048-9068, https://doi.org/10.1002/2016JD025150, 2016.

Bell, T. L., Rosenfeld, D., Kim, K. M., Yoo, J. M., Lee, M. I., and Hahnenberger, M.: Midweek increase in US summer rain and storm heights suggests air pollution invigorates rainstorms, J. Geophys. Res.-Atmos., 113, D02209, https://doi.org/10.1029/2007JD008623, 2008.

Bell, T. L., Rosenfeld, D., and Kim, K. M.: Weekly cycle of lightning: evidence of storm invigoration by pollution, Geophys. Res. Lett., 36, L23805, https://doi.org/10.1029/2009GL040915, 2009.

Betz, H. D., Schumann, U., and Laroche, P.: Lightning: Principles, Instruments and Applications: Review of Modern Lightning Research, Springer Science \& Business Media, https://doi.org/10.1007/978-1-4020-9079-0_1, 2009.

Boccippio, D. J.: Lightning scaling relations revisited, J. Atmos. Sci., 59, 1086-1104, doi:10.1175/15200469(2002)059<1086:LSRR>2.0.CO;2, 2002.

Boccippio, D. J., Goodman, S. J., and Heckman, S.: Regional differences in tropical lightning distributions, J. Appl. Meteorol., 39, 2231-2248, https://doi.org/10.1175/15200450(2001)040<2231:RDITLD>2.0.CO;2, 2000.

Boucher, O., Randall, D., Artaxo, P., Bretherton, C., Feingold, G., Forster, P., Kerminen, V.-M., Kondo, Y., Liao, H., Lohmann, U., Rasch, P., Satheesh, S. K., Sherwood, S., Stevens, B., and Zhang, X. Y.: Clouds and Aerosols. In: Climate Change 2013: The Physical Science Basis. Contribution of Working Group I to the Fifth Assessment Report of the Intergovernmental Panel on Climate Change, edited by: Stocker, T. F., Qin, D., Plattner, G.-K., Tignor, M., Allen, S. K., Boschung, J., Nauels, A., Xia, Y., Bex, V., and Midgley, P. M., Cambridge University Press, Cambridge, United Kingdom and New York, NY, USA, 2013.

Burpee, R. W.: The origin and structure of easterly waves in the lower troposphere of North Africa, J.
Atmos. Sci., 29, 77-90, https://doi.org/10.1175/1520 0469(1972)029<0077:TOASOE>2.0.CO;2, 1972.

Cecil, D. J.: LIS/OTD 2.5 Degree Low Resolution Diurnal Climatology (LRDC). Dataset available online from the NASA Global Hydrology Center DAAC, Huntsville, Alabama, USA, doi:10.5067/LIS/LIS-OTD/DATA307, 2001.

Cecil, D. J.: LIS/OTD 2.5 Degree Low Resolution Monthly Climatology Time Series (LRMTS). Dataset available online from the NASA Global Hydrology Center DAAC, Huntsville, Alabama, USA, doi:10.5067/LIS/LIS-OTD/DATA309, 2006.

Cecil, D. J., Buechler, D. E., and Blakeslee, R. J. Gridded lightning climatology from TRMM-LIS and OTD: dataset description, Atmos. Res., 135, 404-414, https://doi.org/10.1016/j.atmosres.2012.06.028, 2014.

Chakraborty, S., Schiro, K. A., Fu, R., and Neelin, J. D.: On the role of aerosols, humidity, and vertical wind shear in the transition of shallow-to-deep convection at the Green Ocean Amazon 2014/5 site, Atmos. Chem. Phys., 18, 11135-11148, https://doi.org/10.5194/acp-18-11135-2018, 2018.

Christian, H. J., Blakeslee, R. J., Boccippio, D. J., Boeck, W. L., Buechler, D. E., Driscoll, K. T., Goodman, S. J., Hall, J. M., Koshak, W. J., and Mach, D. M.: Global frequency and distribution of lightning as observed from space by the Optical Transient Detector, J. Geophys. Res.-Atmos., 108, ACL-4, https://doi.org/10.1029/2002JD002347, 2003.

Coniglio, M. C., Stensrud, D. J., and Wicker, L. J.: Effects of upperlevel shear on the structure and maintenance of strong quasilinear mesoscale convective systems, J. Atmos. Sci., 63, 12311252, https://doi.org/10.1175/JAS3681.1, 2006.

da Silva, A. M., Randles, C. A., Buchard, V., Darmenov, A., Colarco, P. R., and Govindaraju, R.: File Specification for the MERRA Aerosol Reanalysis (MERRAero). GMAO Office Note No. 7, available at: http://gmao.gsfc.nasa.gov/pubs/office_notes, 2015.

Dee, D. P., Uppala, S., Simmons, A., Berrisford, P., Poli, P., Kobayashi, S., Andrae, U., Balmaseda, M., Balsamo, G., and Bauer, P.: The ERA-Interim reanalysis: configuration and performance of the data assimilation system, Q. J. Roy. Meteorol. Soc., 137, 553-597, https://doi.org/10.1002/qj.828, 2011.

Derbyshire, S. H., Beau, I., Bechtold, P., Grandpeix, J. Y., Piriou, J. M., Redelsperger, J. L., and Soares, P. M. M.: Sensitivity of moist convection to environmental humidity, Q. J. Roy. Meteorol. Soc., 130, 3055-3079, 2004

Fan, J., Zhang, R., Li, G., and Tao, W. K.: Effects of aerosols and relative humidity on cumulus clouds, J. Geophys. Res.-Atmos., 112, https://doi.org/10.1029/2006JD008136, 2007.

Fan, J., Zhang, R., Tao, W. K., and Mohr, K.: Effects of aerosol optical properties on deep convective clouds and radiative forcing, J. Geophys. Res.-Atmos., 113, D08209, https://doi.org/10.1029/2007JD009257, 2008.

Fan, J., Yuan, T., Comstock, J. M., Ghan, S., Khain, A., Leung, L. R., Li, Z., Martins, V. J., and Ovchinnikov, M.: Dominant role by vertical wind shear in regulating aerosol effects on deep convective clouds, J. Geophys. Res.-Atmos., 114, D22206, https://doi.org/10.1029/2009JD012352, 2009.

Fan, J., Leung, L. R., Rosenfeld, D., Chen, Q., Li, Z., Zhang, J., and Yan, H.: Microphysical effects determine macrophysical response for aerosol impacts on deep convec- 
tive clouds, P. Natl. Acad. Sci. USA, 110, E4581-E4590, https://doi.org/10.1073/pnas.1316830110, 2013.

Fan, J., Wang, Y., Rosenfeld, D., and Liu, X.: Review of aerosolcloud interactions: mechanisms, significance and challenges, J. Atmos. Sci., 73, 4221-4252, https://doi.org/10.1175/JAS-D-160037.1, 2016.

Fan, J., Rosenfeld, D., Zhang, Y., Giangrande, S. E., Li, Z., Machado, L. A., and Barbosa, H. M.: Substantial convection and precipitation enhancements by ultrafine aerosol particles, Science, 359, 411-418, 2018.

Feingold, G. and Morley, B.: Aerosol hygroscopic properties as measured by lidar and comparison with in situ measurements, J. Geophys. Res.-Atmos., 108, 4327, doi:10.1029/2002JD002842, 2003.

Goudie, A. and Middleton, N.: Saharan dust storms: nature and consequences, Earth-Sci. Rev., 56, 179-204, doi:10.1016/S00128252(01)00067-8, 2001.

Guo, J., Deng, M., Lee, S. S., Wang, F., Li, Z., Zhai, P., Liu, H., Lv, W., Yao, W., and Li, X.: Delaying precipitation and lightning by air pollution over the Pearl River Delta. Part I: Observational analyses, J. Geophys. Res.-Atmos., 121, 6472-6488, https://doi.org/10.1002/2015JD023257, 2016.

Hintze, J. L. and Nelson, R. D.: Violin plots: a box plot-density trace synergism, Am. Stat., 52, 181-184, https://doi.org/10.1080/00031305.1998.10480559, 1998.

Homeyer, C. R., Schumacher, C., and Hopper Jr., L. J.: Assessing the applicability of the tropical convective-stratiform paradigm in the extratropics using radar divergence profiles, J. Climate, 27, 6673-6686, https://doi.org/10.1175/JCLI-D-13-00561.1, 2014.

Huang, J., Wang, T., Wang, W., Li, Z., and Yan, H.: Climate effects of dust aerosols over East Asian arid and semiarid regions, J. Geophys. Res.-Atmos., 119, 11398-11416, https://doi.org/10.1002/2014JD021796, 2014a.

Huang, J., Li, Y., Fu, C., Chen, F., Fu, Q., Dai, A., Shinoda, M., Ma, Z., Guo, W., Li, Z., Zhang, L., Liu, Y., Yu, H., He, Y., Xie, Y., Guan, X., Ji, M., Lin, L., Wang, S., Yan, H., and Wang, G.: Dryland climate change recent progress and challenges, Rev. Geophys., 55, 719-778, doi:10.1002/2016RG000550, 2014b.

Hubanks, P., Platnick, S., King, M., and Ridgway, B.: MODIS Atmosphere L3 gridded product algorithm theoretical basis document (atbd) \& users guide, ATBD reference number ATBDMOD-30, NASA, 125, 2015.

Ichoku, C., Ellison, L. T., Willmot, K. E., Matsui, T., Dezfuli, A. K., Gatebe, C. K., Wang, J., Wilcox, E. M., Lee, J., and Adegoke, J.: Biomass burning, land-cover change, and the hydrological cycle in Northern sub-Saharan Africa, Environ. Res. Lett., 11, https://doi.org/10.1088/1748-9326/11/9/095005, 2016.

Igel, M. R. and van den Heever, S. C.: The relative influence of environmental characteristics on tropical deep convective morphology as observed by CloudSat, J. Geophys. Res.-Atmos., 120, 4304-4322, https://doi.org/10.1002/2014JD022690, 2015.

Jayaratne, E. R. and Kuleshov. Y.: The relationship between lightning activity and surface wet bulb temperature and its variation with latitude in Australia, Meteorol. Atmos. Phys., 91, 17-24, 2006.

Kaufman, Y. J., Tanre, D., Holben, B., Mattoo, S., Remer, L., Eck, T., Vaughan, J., and Chatenet, B.: Aerosol radiative impact on spectral solar flux at the surface, derived from principal-plane sky measurements, J. Atmos. Sci., 59, 635-646, doi:10.1175/15200469(2002)059<0635:ARIOSS>2.0.CO;2, 2002.

Kaufman, Y. J., Koren, I., Remer, L. A., Rosenfeld, D., and Rudich, Y.: The effect of smoke, dust, and pollution aerosol on shallow cloud development over the Atlantic Ocean, P. Natl. Acad. Sci. USA, 102, 11207-11212, 2005.

Khain, A. P.: Notes on state-of-art investigation of aerosol effects on precipitation: a critical review, Environ. Res. Lett., 4, 015004, https://doi.org/10.1088/1748-9326/4/1/015004, 2009.

Khain, A., Pokrovsky, A., Pinsky, M., Seifert, A., and Phillips, V.: Simulation of effects of atmospheric aerosols on deep turbulent convective clouds using a spectral microphysics mixed-phase cumulus cloud model. Part I: Model description and possible applications, J. Atmos. Sci., 61, 2963-2982, https://doi.org/10.1175/JAS-3350.1, 2004.

Khain, A., Rosenfeld, D., and Pokrovsky, A.: Aerosol impact on the dynamics and microphysics of deep convective clouds, Q. J. Roy. Meteorol. Soc., 131, 2639-2663, https://doi.org/10.1256/qj.04.62, 2005.

Khain, A., BenMoshe, N., and Pokrovsky, A.: Factors determining the impact of aerosols on surface precipitation from clouds: an attempt at classification, J. Atmos. Sci., 65, 1721-1748, https://doi.org/10.1175/2007JAS2515.1, 2008.

Klein, W. H. and Walsh, J. E.: A comparison of pointwise screening and empirical orthogonal functions in specifying monthly surface temperature from $700 \mathrm{mb}$ data, Mon. Weather Rev., 111, 669673, 1983.

Knaff, J. A.: Implications of summertime sea level pressure anomalies in the tropical Atlantic region, J. Climate, 10, 789-804, https://doi.org/10.1175/15200442(1997)010<0789:IOSSLP>2.0.CO;2, 1997.

Koren, I., Kaufman, Y. J., Remer, L. A., and J. V. Martins, J. V.: Measurement of the effect of Amazon smoke on inhibition of cloud formation, Science, 303, 1342-1345, https://doi.org/10.1126/science.1089424, 2004.

Koren, I., Martins, J. V., Remer, L. A., and Afargan, H.: Smoke invigoration versus inhibition of clouds over the Amazon, Science, 321, 946-949, https://doi.org/10.1126/science.1159185, 2008.

Koren, I., Altaratz, O., Remer, L. A., Feingold, G., Martins, J. V., and Heiblum, R. H.: Aerosol-induced intensification of rain from the tropics to the mid-latitudes, Nat. Geosci., 5, 118-122, 2012.

Lee, S. S., Guo, J., and Li, Z.: Delaying precipitation by air pollution over the Pearl River Delta. Part 2. Model simulations, J. Geophys. Res.-Atmos., 121, 11739-11760, https://doi.org/10.1002/2015JD024362, 2016.

Lemaître, C., Flamant, C., Cuesta, J., Raut, J.-C., Chazette, P., Formenti, P., and Pelon, J.: Radiative heating rates profiles associated with a springtime case of Bodélé and Sudan dust transport over West Africa, Atmos. Chem. Phys., 10, 8131-8150, https://doi.org/10.5194/acp-10-8131-2010, 2010.

Levy, R., Mattoo, S., Munchak, L., Remer, L., Sayer, A., Patadia, F., and Hsu, N.: The Collection 6 MODIS aerosol products over land and ocean, Atmos. Meas. Tech., 6, 2989-3034, https://doi.org/10.5194/amt-6-2989-2013, 2013.

Li, Z., Lau, W. M., Ramanathan, V., Wu, G., Ding, Y., Manoj, M., Liu, J., Qian, Y., Li, J., and Zhou, T.: Aerosol and monsoon climate interactions over Asia, Rev. Geophys., 54, 866-929, https://doi.org/10.1002/2015RG000500, 2016. 
Li, Z., Guo, J., Ding, A., Liao, H., Liu, J., Sun, Y., Wang, T., Xue, H., Zhang, H., and Zhu, B.: Aerosol and boundary-layer interactions and impact on air quality, Natl. Sci. Rev., 4, 810-833, https://doi.org/10.1093/nsr/nwx117, 2017a.

Li, Z., Rosenfeld, D., and Fan, J.: Aerosols and their impact on radiation, clouds, precipitation, and severe weather events, Oxford Research Encyclopedias, No. PNNL-SA-124900, https://doi.org/10.1093/acrefore/9780199389414.013.126, 2017b.

Lucas, C., Zipser, E. J., and Lemone, M. A.: Vertical velocity in oceanic convection off tropical Australia, J. Atmos. Sci., 51, 3183-3193, https://doi.org/10.1175/15200469(1994)051<3183:VVIOCO>2.0.CO;2, 1994.

Mansell, E. R. and Ziegler, C. L.: Aerosol effects on simulated storm electrification and precipitation in a two-moment bulk microphysics model, J. Atmos. Sci., 70, 2032-2050, https://doi.org/10.1175/JAS-D-12-0264.1, 2013.

Mapes, B. and Houze Jr., R. A.: An integrated view of the 1987 Australin monsoon and its mesoscale convective systems. II: Vertical structure, Q. J. Roy. Meteorol. Soc., 119, 733-754, https://doi.org/10.1002/qj.49711951207, 1993.

Mapes, B. E. and Houze Jr., R. A.: Diabatic divergence profiles in western Pacific mesoscale convective systems, J. Atmos. Sci., 52, 1807-1828, https://doi.org/10.1175/15200469(1995)052<1807:DDPIWP>2.0.CO;2, 1995.

Markson, R.: Ionospheric potential variation from temperature change over continents, XII International Conference on Atmospheric Electricity, Versailles, France, 9-13 June, 2003.

Markson, R.: The global circuit intensity - its measurement and variation over the last 50 years, B. Am. Meteorol. Soc., 88, https://doi.org/10.1175/BAMS-88-2-223, 2007.

Menon, S., Hansen, J., Nazarenko, L., and Luo, Y.: Climate effects of black carbon aerosols in China and India, Science, 297, 2250 2253, https://doi.org/10.1126/science.1075159, 2002.

Michalon, N., Nassif, A., Saouri, T., Royer, J. F., and Pontikis, C.: Contribution to the climatological study of lightning, Geophys. Res. Lett., 26, 3097-3100, https://doi.org/10.1029/1999GL010837, 1999.

Mitovski, T., Folkins, I., Von Salzen, K., and Sigmond, M.: Temperature, relative humidity, and divergence response to high rainfall events in the tropics: observations and models, J. Climate, 23, 3613-3625, https://doi.org/10.1175/2010JCLI3436.1, 2010.

Nesbitt, S. W. and Zipser, E. J.: The diurnal cycle of rainfall and convective intensity according to three years of TRMM measurements, J. Climate, 16, 1456-1475, https://doi.org/10.1175/15200442-16.10.1456, 2003.

Orville, R. E., Huffines, G., Nielsen-Gammon, J., Zhang, R., Ely, B., Steiger, S., Phillips, S., Allen, S., and Read, W.: Enhancement of cloud-to-ground lightning over Houston, Texas, Geophys. Res. Lett., 28, 2597-2600, https://doi.org/10.1029/2001GL012990, 2001.

Pearson, K.: Mathematical contributions to the theory of evolution. III. Regression, heredity and panmixia, Philos. T. R. Soc. Lond. S-A, 187, 253-318, https://doi.org/10.1098/rsta.1896.0007, 1896.

Platnick, S., King, M. D., Ackerman, S. A., Menzel, W. P., Baum, B. A., Riedi, J. C., and Frey, R. A.: The MODIS cloud products: Algorithms and examples from Terra, IEEE Trans. Geosci. Remote Sens., 41, 459-473, 2003.
Price, C.: Global surface temperatures and the atmospheric electrical circuit, Geophys. Res. Lett., 20, 1363-1366, https://doi.org/10.1029/93GL01774, 1993.

Prospero, J. M., Ginoux, P., Torres, O., Nicholson, S. E., and Gill, T. E.: Environmental characterization of global sources of atmospheric soil dust derived from the Nimbus 7 TOMS absorbing aerosol product, Rev. Geophys., 40, 1002, https://doi.org/10.1029/2000RG000095, 2002.

Redelsperger, J. L., Parsons, D. B., and Guichard, F.: Recovery processes and factors limiting cloud-top height following the arrival of a dry intrusion observed during TOGA COARE, J. Atoms Sci, 59, 2438-2457, 2002.

Reeve, N. and Toumi, R.: Lightning activity as an indicator of climate change, Q. J. Roy. Meteorol. Soc., 125, 893-903, 1999.

Richardson, Y. P., Droegemeier, K. K., and Davies-Jones, R. P.: The influence of horizontal environmental variability on numerically simulated convective storms. Part I: Variations in vertical shear, Mon. Weather Rev., 135, 3429-3455, https://doi.org/10.1175/MWR3463.1, 2007.

Riemann-Campe, K., Fraedrich, K., and Lunkeit, F.: Global climatology of convective available potential energy (CAPE) and convective inhibition (CIN) in ERA-40 reanalysis, Atmos. Res., 93, 534-545, https://doi.org/10.1016/j.atmosres.2008.09.037, 2009.

Roberts, G., Wooster, M. J., and Lagoudakis, E.: Annual and diurnal african biomass burning temporal dynamics, Biogeosciences, 6 , 849-866, https://doi.org/10.5194/bg-6-849-2009, 2009.

Rosenfeld, D. and Lensky, I. M.: Satellite-based insights into precipitation formation processes in continental and maritime convective clouds, B. Am. Meteorol. Soc., 79, 2457-2476, doi:10.1175/1520-0477(1998)079<2457:SBIIPF>2.0.CO;2, 1998.

Rosenfeld, D., Rudich, Y., and Lahav, R.: Desert dust suppressing precipitation: a possible desertification feedback loop, P. Natl. Acad. Sci. USA, 98, 5975-5980, https://doi.org/10.1073/pnas.101122798, 2001.

Rosenfeld, D., Lohmann, U., Raga, G. B., O’Dowd, C. D., Kulmala, M., Fuzzi, S., Reissell, A., and Andreae, M. O.: Flood or drought: How do aerosols affect precipitation?, Science, 321, 1309-1313, https://doi.org/10.1126/science.1160606, 2008.

Rotunno, R., Klemp, J. B., and Weisman, M. L.: A theory for strong, long-lived squall lines, J. Atmos. Sci., 45, 463-485, https://doi.org/10.1175/15200469(2004)061<0361:ATFSLS>2.0.CO;2, 1998.

Shao, Y.: Physics and Modelling of Wind Erosion, Springer Science \& Business Media, 37, 2008.

Stolz, D. C., Rutledge, S. A., and Pierce, J. R.: Simultaneous influences of thermodynamics and aerosols on deep convection and lightning in the tropics, J. Geophys. Res.-Atmos., 120, 62076231, https://doi.org/10.1002/2014JD023033, 2015.

Stolz, D. C., Rutledge, S. A., Pierce, J. R., and van den Heever, S. C.: A global lightning parameterization based on statistical relationships among environmental factors, aerosols, and convective clouds in the TRMM climatology, J. Geophys. Res.-Atmos., 122, 7461-7492, https://doi.org/10.1002/2016JD026220, 2017.

Takemi, T.: A sensitivity of squall-line intensity to environmental static stability under various shear and moisture conditions, Atoms. Res., 84, 374-389, doi:10.1016/j.atmossres.2006.10.001, 2007. 
Tao, W. K., Chen, J. P., Li, Z. Q., Wang, C., and Zhang, C. D.: Impact of aerosols on convective clouds and precipitation, Rev. Geophys., 50, RG2001, https://doi.org/10.1029/2011rg000369, 2012.

Thornton, J. A., Virts, K. S., Holzworth, R. H., and Mitchell, T. P.: Lightning enhancement over major oceanic shipping lanes, Geophys. Res. Lett., 44, 9102-9111, https://doi.org/10.1002/2017GL074982, 2017.

van der Werf, G. R., Randerson, J. T., Collatz, G. J., and Giglio, L.: Carbon emissions from fires in tropical and subtropical ecosystems, Global Change Biol., 9, 547-562, https://doi.org/10.1046/j.1365-2486.2003.00604.x, 2003.

van der Werf, G. R., Randerson, J. T., Giglio, L., Collatz, G. J., Kasibhatla, P. S., and Arellano Jr., A. F.: Interannual variability in global biomass burning emissions from 1997 to 2004, Atmos. Chem. Phys., 6, 3423-3441, https://doi.org/10.5194/acp-6-34232006, 2006.

Venevsky, S.: Importance of aerosols for annual lightning production at global scale, Atmos. Chem. Phys. Discuss., 14, 43033325, https://doi.org/10.5194/acpd-14-4303-2014, 2014.

Waliser, D. E. and Gautier, C.: A satellite-derived climatology of the ITCZ, J. Climate, 6, 2162-2174, https://doi.org/10.1175/15200442(1993)006<2162:ASDCOT>2.0.CO;2, 1993.

Wall, C., Zipser, E., and Liu, C.: An investigation of the aerosol indirect effect on convective intensity using satellite observations, J. Atmos. Sci., 71, 430-447, https://doi.org/10.1175/JAS-D-130158.1, 2014.

Wang, F., Guo, J., Zhang, J., Huang, J., Min, M., Chen, T., Liu, H., Deng, M., and Li, X.: Multi-sensor quantification of aerosol-induced variability in warm cloud properties over eastern China, Atmos. Environ., 113, 1-9, https://doi.org/10.1016/j.atmosenv.2015.04.063, 2015.

Weisman, M. L. and Klemp, J. B.: The dependence of numerically simulated convective storms on vertical wind shear and buoyancy, Mon.Weather Rev., 110, 504-520, https://doi.org/ 10.1175/1520-0493(1982)110<0504:TDONSC > 2.0.CO;2, 1982.

Weisman, M. L., and Rotunno, R.: "A theory for strong long-lived squall lines" revisited, J. Atmos. Sci., 61, 361-382, https://doi.org/10.1175/15200469(2004)061<0361:ATFSLS>2.0.CO;2, 2004.

Westcott, N. E.: Summertime cloud-to-ground lightning activity around major midwestern urban areas, J. Appl. Meteorol., 34, 1633-1642, https://doi.org/10.1175/1520-0450-34.7.1633, 1995.

Williams, E. R.: The Schumann resonance: a global tropical thermometer, Science, 256, 1184-1187, https://doi.org/10.1126/science.256.5060.1184, 1992.

Williams, E. R.: Global circuit response to seasonal variations in global surface air temperature, Mon. Weather Rev., 122, 1917-1929, https://doi.org/10.1175/15200493(1994)122<1917:GCRTSV>2.0.CO;2, 1994.

Williams, E. R.: Global circuit response to temperature on distinct time scales: a status report, Atmospheric and Ionospheric Phenomena Associated with Earthquakes, edited by: Hayakawa, M., 939-949, Terra Sci., Tokyo, 1999.
Williams, E. R.: Lightning and climate: a review, Atmos. Res., 76, 272-287, https://doi.org/10.1016/j.atmosres.2004.11.014, 2005.

Williams, E. R. and Stanfill, S.: The physical origin of the landocean contrast in lightning activity, C. R. Phys., 3, 1277-1292, https://doi.org/10.1016/S1631-0705(02)01407-X, 2002.

Williams, E. R. and Satori, G.: Lightning, thermodynamic and hydrological comparison of the two tropical continental chimneys, J. Atmos. Sol.-Terr. Phy., 66, 1213-1231, https://doi.org/10.1016/j.jastp.2004.05.015, 2004.

Williams, E. R., Rothkin, K., Stevenson, D., and Boccippio, D.: Global lightning variations caused by changes in thundersotmr flash rate and by changes in the number of thunderstorms, J. Appl. Meteorol., 39, 2223-2230, https://doi.org/10.1175/15200450(2001)040<2223:GLVCBC>2.0.CO;2, 2000.

Williams, E. R., Rosenfeld, D., Madden, N., Gerlach., J., and Avelino, E.: Comparison convective regimes over the Amazon: implications for cloud electrification, J. Geophys. Res.-Atmos., 107, 8082, https://doi.org/10.1029/2001JD000380, 2002.

Williams, E. R., Chan, T., and Boccippio, D.: Islands as miniature continents: another look at the landocean lightning contrast, J. Geophys. Res.-Atmos., 109, https://doi.org/10.1029/2003JD003833, 2004.

Williams, E. R., Mushtak, V., Rosenfeld, D., Goodman, S., and Boccippio, D.: Thermodynamic conditions favorable to superlative thunderstorm updraft, mixed phase microphysics and lightning flash rate, Atmos. Res., 76, 288-306, https://doi.org/10.1016/j.atmosres.2004.11.009, 2005.

Xiong, Y. J., Qie, X. S., Zhou, Y. J., Yuan, T., and Zhang, T. L.: Regional response of lightning activities to relative humidity of the surface, Chin. J. Geophys., 49, 311-318, 2006.

Yuan, T., Remer, L. A., Pickering, K. E., and Yu, H.: Observational evidence of aerosol enhancement of lightning activity and convective invigoration, Geophys. Res. Lett., 38, L04701, https://doi.org/10.1029/2010GL046052, 2011.

Zhang, G. J.: Effects of entrainment on convective available potential energy and closure assumptions in convection parameterization, J. Geophys. Res.-Atmos., 114, D07109, https://doi.org/10.1029/2008JD010976, 2009.

Zhao, C., Tie, X., and Lin, Y.: A possible positive feedback of reduction of precipitation and increase in aerosols over eastern central China, Geophys. Res. Lett., 33, L11814, https://doi.org/10.1029/2006GL025959, 2006.

Zipser, E. J. and Lutz, K. R.: The vertical profile of radar reflectivity of convective cells: a strong indicator of storm intensity and lightning probability?, Mon. Weather Rev., 122, 1751-1759, https://doi.org/10.1175/15200493(1994)122<1751:TVPORR>2.0.CO;2, 1994. 